\title{
Axonal Gap Junctions Between Principal Neurons: A Novel Source of Network Oscillations, and Perhaps Epileptogenesis
}

\author{
Roger D. Traub', Andreas Draguhn², Miles A. Whittington ${ }^{3}$, Torsten Baldeweg ${ }^{4}$, \\ Andrea Bibbig ${ }^{1}$, Eberhard H. Buhl ${ }^{3}$ and Dietmar Schmitz ${ }^{5}$ \\ I'Departments of Physiology, Pharmacology and Neurology, SUNY Downstate Medical Center, Brooklyn, NY, USA, \\ ${ }^{2}$ Institute of Physiology, Charité, Humboldt University Berlin, Berlin, Germany, \\ ${ }^{3}$ School of Biomedical Sciences, University of Leeds, Leeds, UK, \\ ${ }^{4}$ Institute of Child Health and Great Ormond Street Hospital, University College London Medical School, \\ London, UK and ${ }^{5}$ Department of Cellular and Molecular Pharmacology, \\ University of California San Francisco, San Francisco, CA, USA
}

\section{SYNOPSIS}

We hypothesized in 1998 that gap junctions might be located between the axons of principal hippocampal neurons, based on the shape of spikelets (fast prepotentials), occurring during gap junction-mediated very fast $(\sim 200 \mathrm{~Hz})$ network oscillations in vitro. More recent electrophysiological, pharmacological and dyecoupling data indicate that axonal gap junctions exist; so far, they appear to be located about 100 $\mu \mathrm{m}$ from the soma, in CA1 pyramidal neurons. Computer modeling and theory predict that axonal gap junctions can lead to very fast network oscillations under three conditions: a) there are spontaneous axonal action potentials; b) the number of gap junctions in the network is neither too low (not less than $\sim 1.5$ per cell on average), nor too high (not more than $\sim 3$ per cell on average); c) action potentials can cross from axon to axon via gap junctions. Simulated oscillations resemble biological ones, but condition (c) remains to be demonstrated directly. Axonal network oscillations can, in turn, induce oscillatory activity in larger neuronal networks,

Accepted: 2 January, 2002

Reprint address:

Dr. Roger D. Traub

Departments of Physiology, Pharmacology and Neurology

SUNY Downstate Medical Center

450 Clarkson Ave.

Box 29

Brooklyn, NY 11203, USA

e-mail: roger.traub@downstate.edu by a variety of mechanisms. Axonal networks appear to underlie in vivo ripples $(\sim 200 \mathrm{~Hz}$ field potential oscillations superimposed on physiological sharp waves), to drive gamma $(30-70 \mathrm{~Hz})$ oscillations that appear in the presence of carbachol, and to initiate certain types of ictal discharge. If axonal gap junctions are important for seizure initiation in humans, there could be practical consequences for antiepileptic therapy: at least one gap junction-blocking compound, carbenoxolone, is already in clinical use (for treatment of ulcer disease), and it crosses the blood-brain barrier.

\section{KEY WORDS}

spikelet, fast prepotential, d-spike, hippocampus, electrical coupling, cortical dysplasia, ripple, seizure

\section{SPIKELETS AND VERY FAST OSCILLATIONS}

Recordings of "spikelets" or "fast prepotentials" - potentials resembling small action potentials, a few $\mathrm{mV}$ in amplitude - in the somata of hippocampal neurons go back 40 years. Spencer and Kandel /66/ observed them as spontaneous events in cat hippocampal neurons in vivo. Spencer and Kandel discussed the possibility that fast prepotentials might arise in the axon and conduct decrementally to the soma, as was suggested earlier to occur in feline spinal motorneurons, when antidromic spikes "blocked" in the axon, not too far from the soma $/ 15 /$; they preferred, however, the 
hypothesis that fast prepotentials arose from active electrogenesis in dendrites, particularly apical dendrites. This latter hypothesis proved extraordinarily fruitful in a multitude of later studies of dendritic electrogenesis (e.g. /43,71,98/). Indeed, there is evidence that - at least under some circumstances - action potentials can be initiated in hippocampal dendrites, rather than the more usual axonal site(s) $/ 28 /$.

Schwartzkroin and Prince $163 /$ noted that spikelets - which they call "d-spikes", assuming a dendritic origin - were particularly likely to occur in CA1 pyramidal cells during epileptiform bursts in disinhibited slices. Knowles and Schwartzkroin 138/ observed spikelets in CA1 pyramidal cells in vitro, after alvear stimulation at some distance from the recorded neuron, suggesting the possibility of an axonal origin for the spikelets.

MacVicar and Dudek $/ 45,46 /$, however, proposed that spikelets represented coupling potentials between nearby neurons interconnected by a (presumably perisomatic) gap junction, under conditions when one of the neurons fired. For example, strong mossy fiber stimulation would evoke an antidromic spike in a particular granule cell; a somewhat weaker stimulation would, however, evoke only a spikelet, with latency slightly delayed $(\sim 0.3 \mathrm{~ms})$ compared to the original antidromic spike. The interpretation was that the stimulus no longer excited the axon of the recorded neuron, but did excite the axon of a nearby, electrically coupled neuron. When the soma of this coupled neuron fired, it was postulated to then induce, via the gap junction, the spikelet which was observed in the recorded neuron. This type of protocol has been extremely useful in our own studies, although - in light of newer data - our interpretation is not exactly the same as that of MacVicar and Dudek. That is, our data show that the spikelet is, indeed, a type of coupling potential, although not a perfectly straightforward one; but the location of the gap junction is somewhere unexpected (see below).

Carlen and colleagues /57,92/ were interested in so-called field bursts $/ 31,73,74 /$, spontaneous runs of large population spikes that occur in low $\left[\mathrm{Ca}^{2+}\right]_{0}$ media (rendering neurons hyperexcitable, while blocking synaptic transmission), events that are
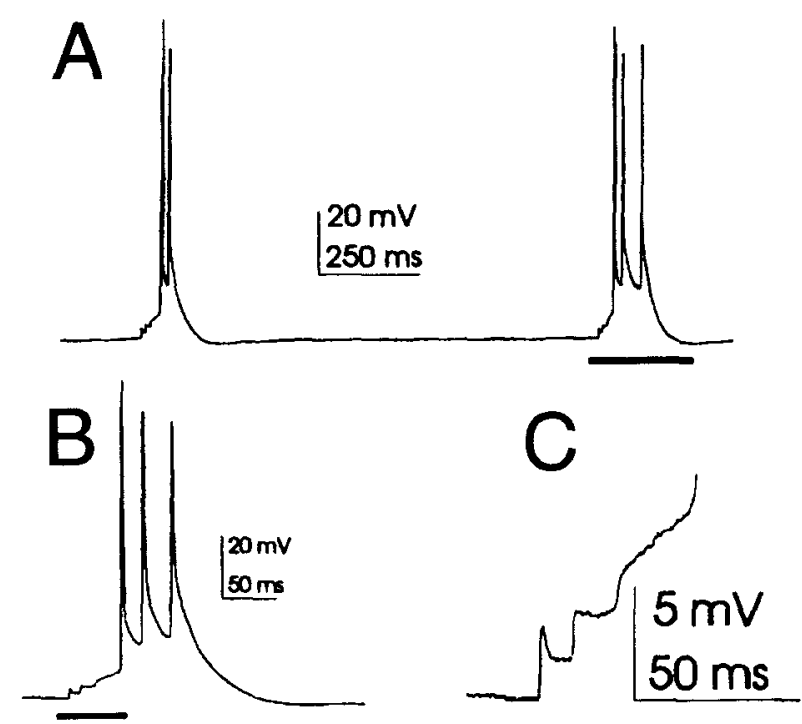

Fig. 1: In low $\left[\mathrm{Ca}^{2+}\right]_{0}$ media, hippocampal pyramidal neurons exhibit bursts that may be preceded by a run of spikelets. The neuron was held hyperpolarized. B shows an expansion of the region in $\mathbf{A}$ marked with a bar. $\mathbf{C}$ shows an expansion of the region in B marked with a bar. A series of spikelets (fast prepotentials) precedes each burst. From 157/, reproduced with permission. $\mathbb{C} 1994$, Society for Neuroscience.

especially prominent in CA1. The precisely locked timing of action potentials during the field burst had been attributed to "field effects", that is, to effects on membrane excitability mediated by currents flowing in the extracellular medium 131,73,74/. Such a mechanism seemed plausible, given the large amplitude of the extracellular potentials $(>5 \mathrm{mV})$, and computer modeling also seemed consistent $/ 78 /$. Nevertheless, Carlen and colleagues provided data suggesting another point of view 157/: first, field bursts are blocked by compounds that block gap junctions (although such drugs can have non-specific side effects); secondly, the existence of dye coupling vetween principal cells was confirmed, and it was noted that the incidence of such coupling increases in low $\left[\mathrm{Ca}^{2+}\right]_{0}$ media. Finally, spontaneous spikelets are prominent in low $\left[\mathrm{Ca}^{2+}\right]_{0}$ media, and spikelets may lead into a burst of action potentials (Fig. 1). These data again indicated that principal hippocampal neurons might indeed be electrically coupled through gap junctions; and, furthermore, that such electrical coupling could contribute, in some important way, to population bursts. 
The link between gap junction-mediated electrical coupling, on the one hand, and population events, on the other hand, was further strengthened by the data of Draguhn et al. $120 \%$. We there reported that small (usually $<200 \mu \mathrm{V}$ ) "mini population spikes" could occur spontaneously, in vitro, in normal media, and were organized into fast runs, often at about $200 \mathrm{~Hz}$ (Fig. 2). We shall call such runs "p-ripples": "ripples" because the events occur at similar frequencies to so-called ripples in vivo $/ 10,102 /$; and "p" to stand for "population spike" - in contradistinction to "i-ripples", fast runs of IPSPs (see below). (In vivo ripples resemble iripples more than they do p-ripples.) p-ripples were found to possess the following important properties:

1. p-ripples have the appearance of small population spikes in that there is a sharp negativity in $\mathrm{s}$. pyramidale, followed by a slightly broader positive wave. p-ripples can only be recorded in principal cell layers, $s$. pyramidale and $s$. granulosum, not in dendritic layers.
2. p-ripples do not simply reflect unit activity, as they are coherent over $>100 \mu \mathrm{m}$. In addition, simultaneous field and patch recordings (Fig. 2, data obtained in low $\left[\mathrm{Ca}^{2+}\right]_{0}$ solution) show that a cell can fire without inducing a minipopulation spike; and, in addition, a minipopulation spike can occur without a full action potential in the index cell.

3. p-ripples do not depend on chemical synapses: they persist (in fact, are enhanced) in low $\left[\mathrm{Ca}^{2+}\right]_{0}$ media in which evoked synaptic potentials disappear.

4. p-ripples require gap junctions for their expression: alkalinization, which opens gap junctions 167/, enhances p-ripples, while rebound acidification suppresses them. Gap junction blocking agents (halothane, carbenoxolone, octanol) suppress p-ripples, in some cases reversibly. Low $\left[\mathrm{Ca}^{2+}\right]_{0}$ media also promote the opening of gap junctions, via intracellular alkalinization $162 \%$.

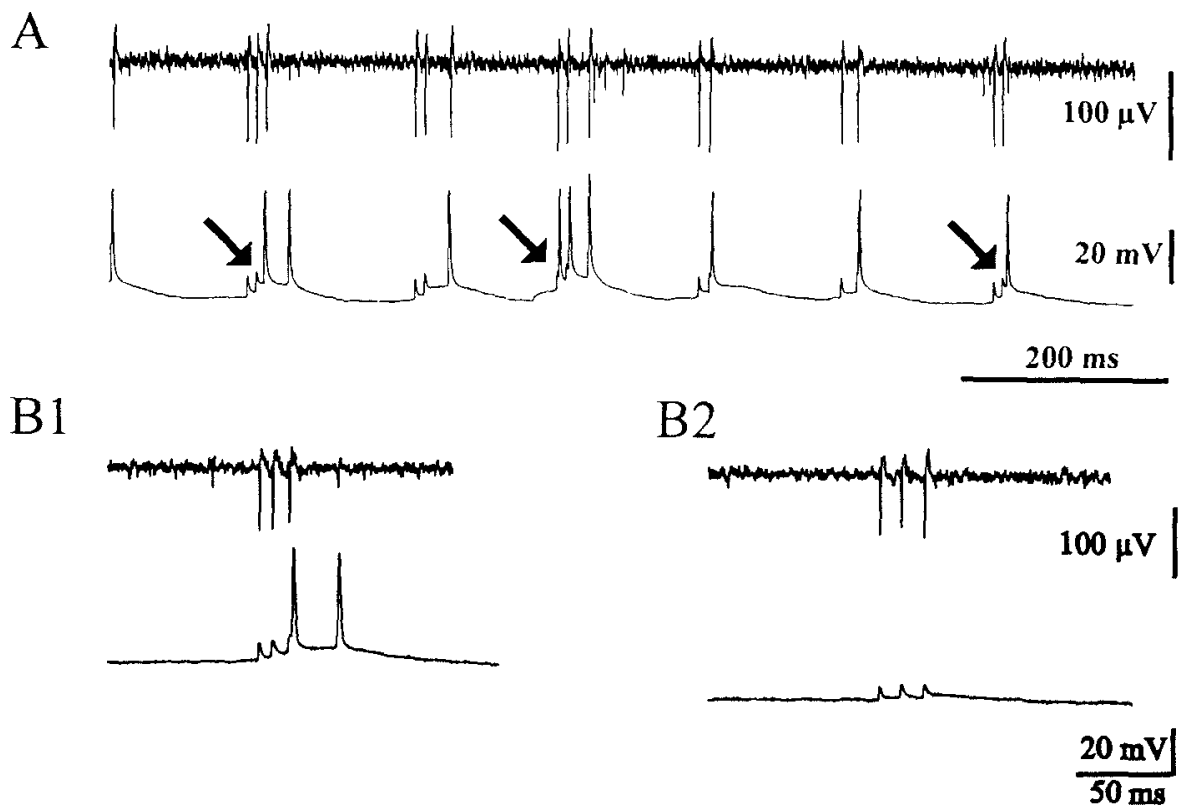

Fig. 2: In low $\left|\mathrm{Ca}^{2+}\right|_{0}$ media, hippocampal pyramidal neurons collectively generate very fast oscillations $(\sim 200 \mathrm{~Hz}$ in this case), the intracellular correlate of which consists of spikelets and full action potentials. Upper traces are stratum pyramidale field potentials ( $\mathrm{CAl}$ ) and lower traces are simultaneous whole-cell recordings from a $\mathrm{CA} 1$ pyramidal neuron. Each of the small population spikes in the field correlates with either a full action potential, or with a spikelet in the cell. The cell sometimes fires as well without a field correlate. The spikelets appear to be electrical coupling potentials, as the population activity requires gap junctions, but not chemical synapses. and many of the spikelets are temporally correlated with population spikes. Spikelets have a rapid rise and fall. Note as well the spikelets followed by an action potential that may exhibit a notch (arrows). From $/ 20 /$, reproduced with permission. 
Figure 2 demonstrates not only the occurrence of spikelets in an individual principal cell, but also the fact that each spikelet occurs at about the same time as a small population spike. It is therefore likely that the spikelet is caused by the firing of one or more principal cells. But caused how? Synaptic transmission was blocked in the experiment shown in Figure 2. The spikelet is unlikely to result from field effects: the extracellular fields are minuscule; and the field consequence of a population spike on a single neuronal soma is to produce a negative transient $/ 74 /$ - whereas the spikelet is a positive transient. By exclusion, if there is a causal relationship between the small population spike and the spikelet, it must be via gap junctions, which are known, in any case, to be critical for the p-ripples to occur at all. This conclusion is consistent with the thinking of MacVicar and Dudek.

\section{THE HYPOTHESIS OF AXON-AXON GAP JUNCTIONS, AND DATA SUPPORTING IT}

In the paper by Draguhn et al. $120 /$, we tried simulations of pairs of electrically coupled pyramidal cells, using a model pyramidal cell developed earlier 179/. Gap junctions were placed between somata or between various homologous sites in the dendrites, both apical and basal. In no case did the simulated coupling potentials match the shape of the experimentally observed spikelets, being too slow and smooth in upstroke, and also decaying too slowly. The gap junction was behaving according to its classical description as a low-pass filter $/ 4 /$. The soma of a neuron is, however, in a sense "electrically coupled" to its own axon - not through a gap junction, but because of the continuity of the axonal and somatic membranes, and axonal and somatic cytoplasm. An axonal spike might be both large, and also narrow, so that the "coupling potential" induced in the soma, by the proximal axonal spike, might resemble the rapidly rising/ rapidly decaying spikelet. This intuition led to an alternative hypothesis, shown in Figure 3.

Suppose (Fig. 3) that the gap junction is located between axons, rather than between somata. If the axon of cell 1 fires, say after antidromic stimulation, there are two processes linking such firing to a coupling potential in the soma of cell 2 . First, how

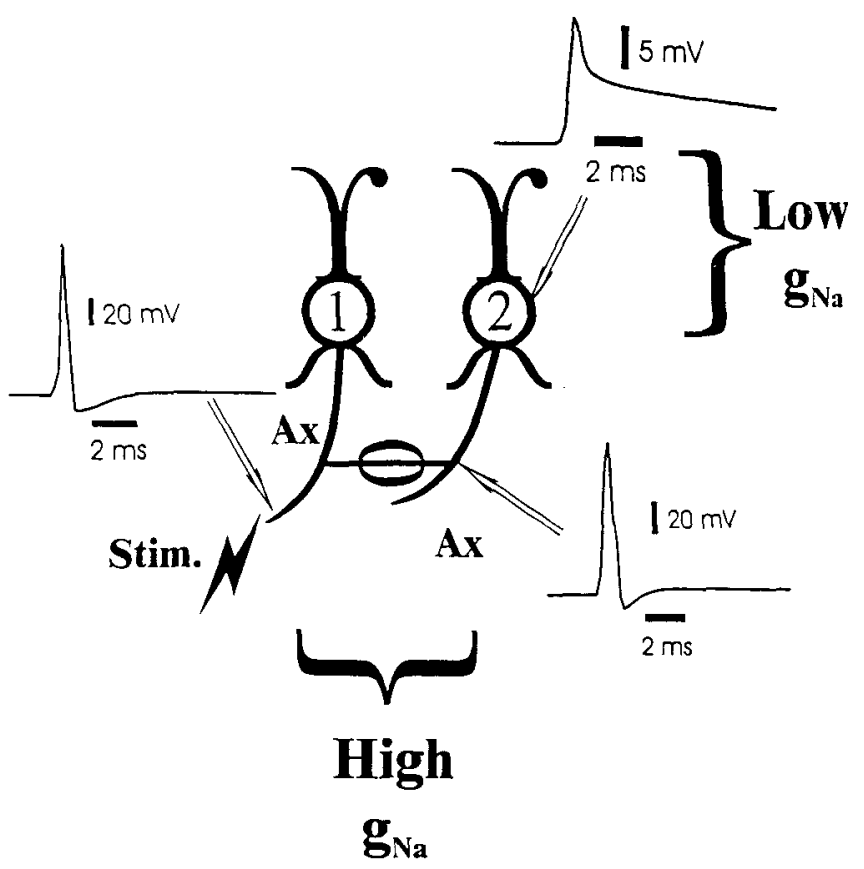

Fig. 3: Diagram illustrating how an axonal gap junction allows a full spike in one axon to induce a spikelet in the soma of a coupled neuron. The axon of cell 1 is stimulated antidromically. If the resulting axonal spike can cross the gap junction to elicit a spike in the axon of cell 2 , that axonal spike can in turn propagate decrementally to the soma of cell 2, eliciting a spikelet. Traces shown are simulation data, as in $/ 62 /$.

is cell 1's axonal spike coupled to cell 2's axon at the site of the gap junction (shown as a sideways $\Phi)$ ? In the simulation of Figure 3 , the gap junction conductance was chosen so that cell 2's axon was induced to fire; given the high input resistance in the axon, and the high density of $\mathrm{Na}^{+}$channels, this is not difficult to do. Second, how is the axonal spike in cell 2 coupled to a somatic event in cell 2 ? In this example, the spike conducts decrementally, because of $\mathrm{K}$ conductances activated by previous activity. The result of such decremental conduction is a spikelet that closely resembles experimental recordings. In other cases, the axonal spike might induce a full antidromic action potential in cell 2, or induce a smaller action potential ("partial spike") in the range of $20 \mathrm{mV}$ or so. 
A variety of experiments are consistent with the scheme shown in Figure 3 and, so far as we are aware, the experiments are not consistent with other schemata. We now summarize some of the data, recently published by Schmitz et al. $/ 62 /$.

Recordings were made with the whole-cell technique of principal hippocampal neurons, mostly $\mathrm{CA} 1$, but also CA3 and dentate granule cells. The majority of the recordings were performed in low $\left[\mathrm{Ca}^{2+}\right]_{0}$ media, but some were done in standard media, in order to document that spikelets do not require low $\left[\mathrm{Ca}^{2+}\right]_{0}$ for their expression.
Stimulation of the axon of the recorded neuron would evoke a typical antidromic spike, but spots could be found $20-200 \mu \mathrm{m}$ away, stimulation of which would evoke an antidromic spike with a notch on its rising phase (Fig. 4A1, cf. Fig. 2). Reducing the stimulus strength could then evoke the isolated spikelet (Fig. 4A2, cf. Fig. 3). The spikelet amplitude sometimes appeared at two different amplitude levels, but in each case the spikelet was blocked by hyperpolarizing the soma of the recorded neuron (Fig. 4A2). Spikelets could follow repetitive stimulation, $1: 1$, at frequencies up
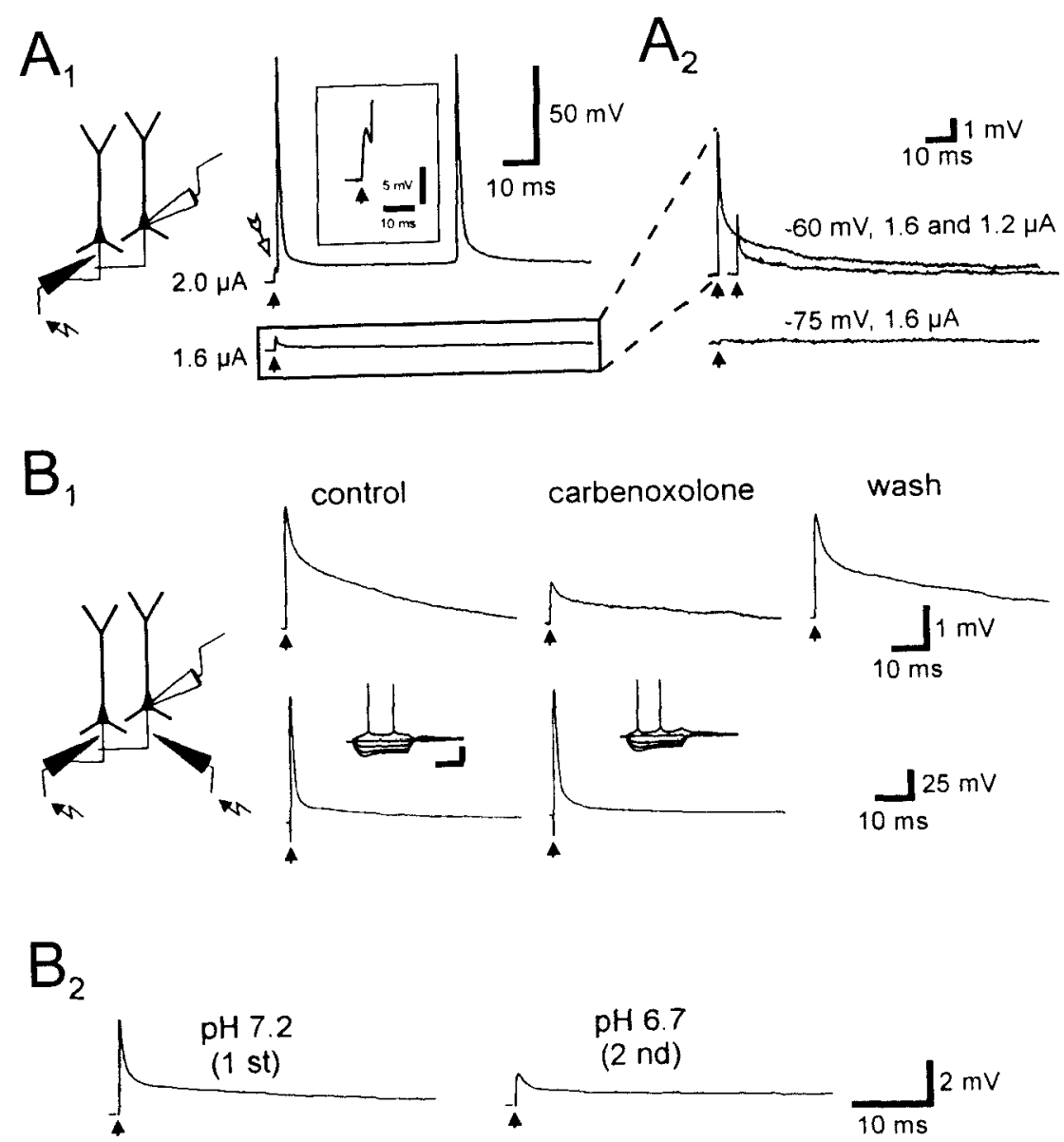

Fig. 4: The gap-junction blocking compound carbenoxolone attenuates spikelets induced by axonal stimulation. A: Direct stimulation of the axon evokes an antidromic spike (not shown), but if the stimulating electrode (filled one, in the schematic) is moved away in the alveus, then stimulation evokes a spikelet followed by an action potential, with a notch in between. Reduction of the stimulus amplitude evokes the spikelet alone. the amplitude of which may be graded with stimulus intensity (A2). Hyperpolarization of the neuron with injected current blocks the spikelet. B 1: Carbenoxolone $(100 \mu \mathrm{M})$ in the bath reversibly attenuates spikelets evoked in this manner. Control traces below show that input resistance, current-evoked spikes and antidromic spikes are not affected by carbenoxolone. Direct recordings from axons and presynaptic terminals (not shown) also revealed no effect of carbenoxolone on intrinsic membrane properties. B2: Intracellular acidification (expected to reduce gap junction conductance) also attenuates spikelets evoked as in $\mathbf{A}$. Data from 62 , reproduced with permission. 
to $500 \mathrm{~Hz}$, characteristic of an axonally-mediated response, but not of a dendritically-mediated response $/ 48 /$. Spikelets were blocked by intracellular QX314: we interpret this finding as reflecting suppression of the active (even if decremental) conduction from the site of the gap junction (in the axon of the recorded neuron) to the soma of the recorded neuron (Fig. 3).

Further consistent with the scheme shown in Figure 3 (and the insets in Fig. 4), the amplitude and rate of rise of the spikelet were both reduced by carbenoxolone (Fig. 4), indicating that a gap junction lies in the path between the stimulus and the recorded spikelet. Several controls were undertaken concerning possible non-specific actions of carbenoxolone. For example, as in Figure 4, antidromic spikes, evoked by direct nearby stimulation, were not affected by the drug. In addition, axonal action potentials, recorded either directly from proximal axons or from mossy fiber presynaptic terminals, were also not affected by the drug $/ 62 /$. It is interesting that carbenoxolone did not suppress spikelets completely, and the effects of the drug could be simulated by reduction of the putative gap junction conductance by $<50 \%$.

Finally, intracellular acidification (expected to reduce gap junctional conductance) also reduced the amplitude and rate-of-rise of the spikelet (Fig. 4B2).

Figure 5 shows simulations that demonstrate how the response in cell 2 (following the schematic of Fig. 3, called the "post" or "post-gap junction" cell in Fig. 5) depends on membrane potential. Each column of Figure $5(\mathrm{~A}, \mathrm{~B}, \mathrm{C})$ is from a single simulation of two pyramidal neurons in the configuration of Figure 3 . The distal axon of cell 1 ("pre axon") was induced to fire in each case, with a current pulse. Each column also shows the axon of cell 2 ("post axon"), initial segment of cell 2 ("post i.s."), and the soma of cell 2. The simulations differ in the holding current in the soma of cell 2 , with successive columns having the soma progressively more hyperpolarized $(\mathrm{A} \rightarrow \mathrm{B} \rightarrow \mathrm{C})$. In each of the three cases, the axonal spike in cell 1 induces an axonal spike in cell 2 . The propagation of cell 2's axonal spike toward the soma differs, however. In A, there is decremental conduction of the axonal spike, leading to a spikelet, which is

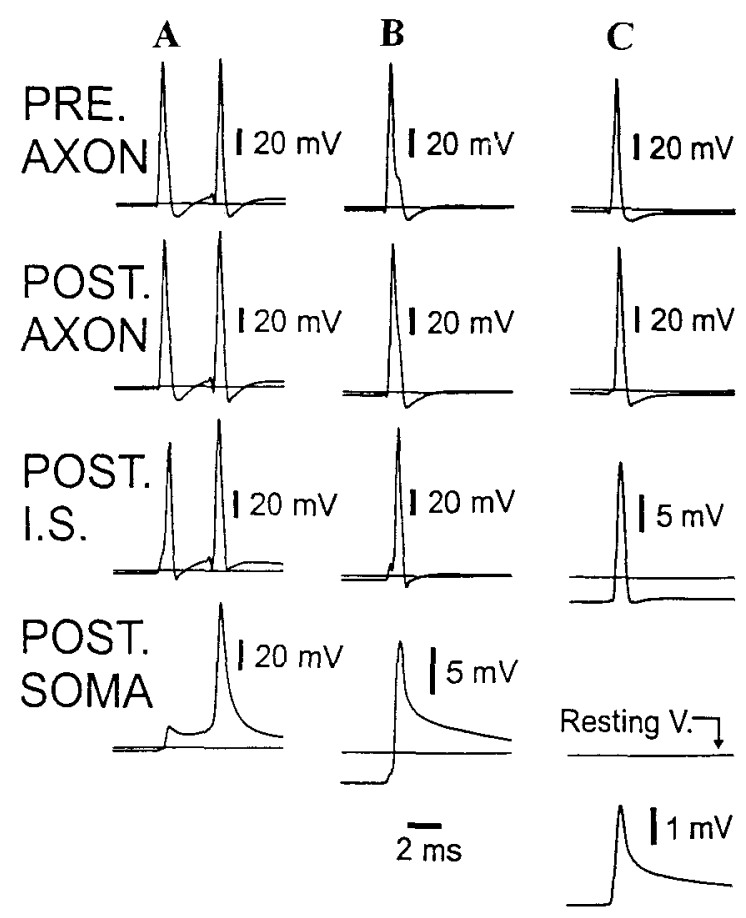

Fig. 5: If two principal neurons are coupled by an axonal gap junction, of conductance sufficient to allow passage of a spike from axon to axon, the coupling potential observed in the "postsynaptic" soma will depend on membrane potential (simulations). Simulations were performed of two model pyramidal neurons, coupled in the axonal compartment just distal to the initial segment, as in Fig. 8 of $/ 62 /$. An antidromic action potential was evoked in the distal axon of the "pre" neuron, while the soma of the "post" neuron was held at different potentials relative to its usual resting potential (indicated by horizontal line in the lowest traces). The holding potential is progressively more hyperpolarized in the sequence $\mathrm{A} \rightarrow \mathrm{B} \rightarrow \mathrm{C}$. A: The "pre" axonal spike (top) crosses the gap junction to produce a spike in the "post" axon $\left(2^{\text {nd }}\right.$ trace); this propagates into the initial segment, evoking a spikelet in the "post" soma that does not fully repolarize, and that leads to a delayed action potential (cf. Figs. 1, 2 and 4). The delayed action potential then propagates orthodromically as a $2^{\text {nd }}$ axonal spike, also evoking a $2^{\text {nd }}$ axonal spike in the "pre" axon. B: At a slightly more hyperpolarized somatic potential in the "post" cell, the "post" axonal spike produces a ful] spike in the initial segment, but only an $\sim 15 \mathrm{mV}$ "partial spike" in the soma. A $2^{\text {nd }}$ axonal spike does not occur. C: When the soma of the "post" cell is still more hyperpolarized, the axonal spike on the "pre" side can still evoke a full action potential in the "post" axon, but this propagates decrementally into the initial segment and soma of the "post" neuron, producing a spikelet of $\sim 2.5 \mathrm{mV}$. (R.D. Traub, unpublished data.) 
then followed by a delayed antidromic spike (as in the inset in Fig. 4A). (The delayed spike in turn produces a second axonal spike.) In $\mathrm{B}$, decremental conduction leads to a large spikelet, about $12 \mathrm{mV}$. In $\mathrm{C}$, during larger hyperpolarization of the soma of cell 2 , the spikelet is only about $2.5 \mathrm{mV}$. Shunting of the proximal axon would be expected to exert a similar effect.

While Figure 5 provides physical insight, it does not account for the stimulus-dependence of the responses shown in Figure 4A. We presume that large and nearby stimulation excites the axon of cell 2 directly. Only distant stimulation has a chance of exciting the axon of cell 1 without exciting the axon of cell 2. Even so, it is not apparent why the spikelet amplitude is variable under conditions in which the membrane potential of cell 2 is held constant. We presume that the axon of cell 2 is contacted (at least sometimes) by more than one "presynaptic" axon - a reasonable assumption (see below).

Given that it is technically feasible to record simultaneously from the soma and proximal axon of cell 2 (see below), a further test of the scheme shown in Figure 3 involves the relative timing of the spikelet in the soma vs the axon of cell 2 (Fig. 6). As the pharmacology suggests that a gap junction interconnects cells 1 and 2, could the gap junction be located anywhere but the axon? If we assume that the gap junction interconnects homologous structures in cells 1 and 2, then dendritic sites lead to the spikelet's appearing in cell 2's soma before cell 2's axon (Fig. 6-I, 6-II). Of course, a site in the axon, distal to the axonal recording site, leads to a situation in which the spikelet appears first in cell 2's axon (Fig. 6-III).

In simultaneous dual recording experiments (Fig. 7), from axon + soma, or from soma + apical dendrite, with the experimental protocol otherwise as in Figure 4, the spikelet in cell 2 always appeared first in the axon, then the soma, then the apical dendrite. Such data imply that the gap junction must be located in the axon of cell 2 .

One theoretical possibility, however, is that even if the gap junction is in the axon of cell 2 - the gap junction is not in the axon of cell 1. For example, the stimulus might excite one or more basal dendrites of cell 1 , and the gap junction(s) lie

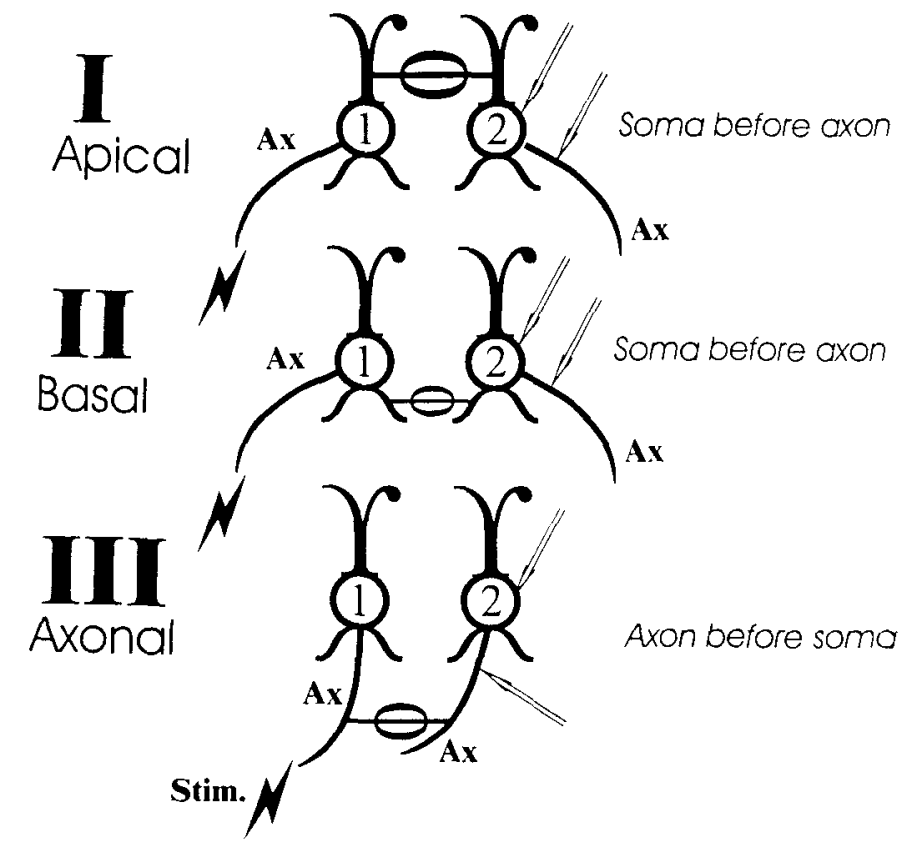

Fig. 6: Appearance of a spikelet in the proximal axon, prior to appearance in the soma of the same neuron, implies that the gap junction lies between axons, and not between dendrites. I. Two principal neurons electrically coupled by a hypothetical gap junction between apical dendrites. Suppose one stimulates the axon of cell 1 at some distance from its soma, causing the axon to fire and generate an antidromic response in cell 1 . Cell 2 is recorded with two nearby electrodes, one on the soma and the other on the proximal axon. The antidromic spike in cell 1 will lead to depolarizations in cell 2 that begin in the soma prior to the axon. (In addition, the depolarization in the soma of cell 2 will have both slower rise and slower decay times than observed experimentally - see Fig. 4 of 120\%) II. Same as I, but now the hypothetical gap junction is between basal dendrites. Again, the depolarization in the soma of cell 2 will begin prior to the axon of cell 2. III. If the gap junction is in the axon, distal to the axonal recording electrode, then the depolarization in cell 2's axon will begin before that in cell 2's soma. In addition, because conduction along cell 2's axon is active (even if decremental), the rise and decay times of the somatic spikelet will be shortened relative to the case of dendritic coupling.

between basal dendrite(s) and axon. One would not expect the basal dendrite to able to follow $500 \mathrm{~Hz}$ stimuli faithfully (see above), but such a possibility still deserves consideration. Morphological infor- 


\section{a

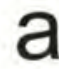

Spikelet
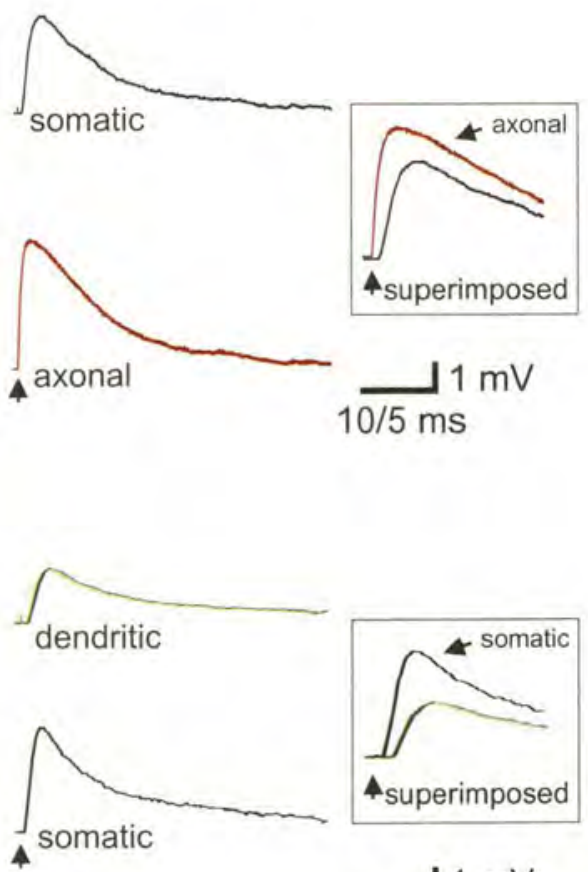

$\underset{10 / 5 \mathrm{~ms}}{1} \mathrm{mV}$

Fig. 7: In simultaneous somatic/proximal axonal, or somatic/dendritic, recordings in low $\left[\left.\mathrm{Ca}^{2+}\right|_{0}\right.$ media, with stimulation in s. oriens, spikelets appear first in the axon, then the soma, then the apical dendrite. This is consistent with a location of the gap junction(s) between axons. Spikelets were evoked as in Fig. 4, with simultaneous whole-cell patch recordings from proximal axon (red) and soma (a), or soma and dendrite (green) (b, different cell). Spikelets appear in the axon before the soma, and in the soma before the apical dendrite. Stimulation artifacts were reduced by subtracting traces obtained in TTX $(0.5 \mu \mathrm{M})$ and were partially clipped. From $/ 62 /$, reproduced with permission.

mation is clearly important, in order to visualize the site of coupling directly.

In order to visualize the site of coupling, visually identified principal neurons were filled with a fluorescent dye using whole-cell "patchclamp" techniques, and secondarily filled neurons were examined. The apparatus allowed multiple images ("stacks") to be taken at high resolution; and the apparatus allowed this entire process to be repeated every $15-30 \mathrm{~s}$. The combination of these features allowed identification of both the primary and secondarily filled cells as being pyramidal (because of possessing spiny dendrites, and because of the pattern of axon collaterals); and it also allowed one to determine which exact processes of the neurons were coupled. The coupled processes of each neuron lay in s. oriens, were lacking in spines, and possessed collaterals branching at near right angles - hence the coupled processes appeared to be axons. The coupling site was in the range of $65-117 \mu \mathrm{m}$ in four instances in CA1 pyramidal cell pairs. In CA3 pyramidal neurons, myelination has been reported to begin $50-120 \mu \mathrm{m}$ from the soma $140 /$.

\section{Vertebrate precedents for axonal gap junctions}

We are not aware of precedents for the axonal coupling of telencephalic neurons. Axonal gap junctions have been reported, however, in the retina 193/, between nodes of Ranvier in commissural 

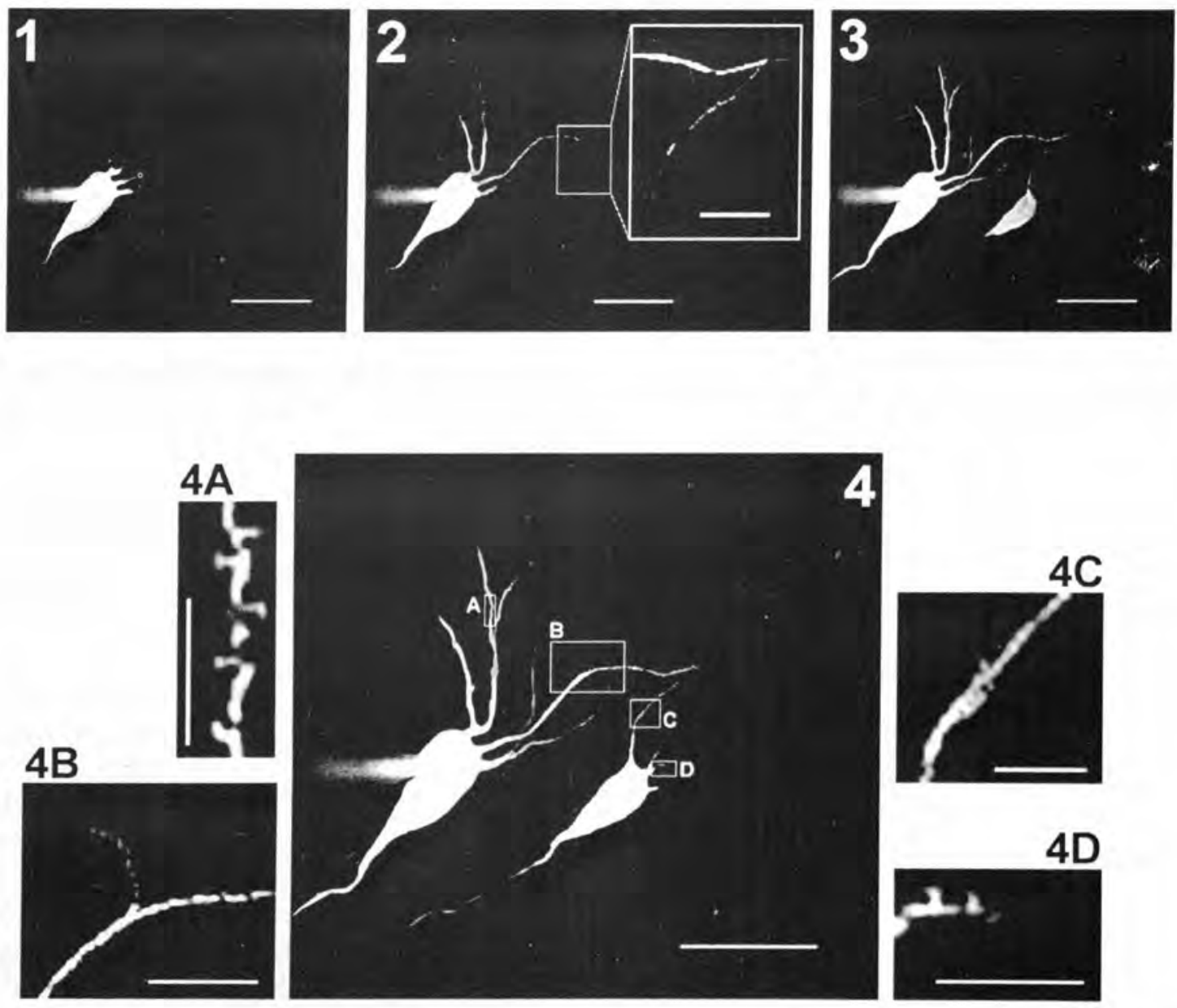

Fig. 8: Morphological evidence for an axonal gap junction between two CA1 pyramidal cells in low $\left[\left.\mathrm{Ca}^{2+}\right|_{0}\right.$ medium. The cell on the left (A, scale bar $50 \mu \mathrm{m}$ ) was loaded with rhodamine-123, with the optics arranged so that multiple images, in planes $1-2 \mu \mathrm{m}$ thick, could be acquired every $15-30 \mathrm{~s}$. The loaded cell is a pyramidal cell, because it possesses spiny dendrites (4A) (scale bar $5 \mu \mathrm{m}$ ). The site of coupling to another neuron is shown in the boxed region in (2) (scale bars 50 $\mu \mathrm{m}, 10 \mu \mathrm{m}$ ). The second neuron, seen in (3) (scale bar $50 \mu \mathrm{m}$ ) and (4) (scale bar $50 \mu \mathrm{m}$ ), is also a pyramidal cell, as it, too, has spiny dendrites (4D) (scale bar $5 \mu \mathrm{m}$ ). The processes of cells 1 and 2 both appear to be axons, as they lack spines and have collaterals branching off at $\sim 90^{\circ}$ into oriens ( $4 \mathrm{~B}$ and $4 \mathrm{C}$ ) (scale bars $10 \mu \mathrm{m}$ ). The site of coupling on the axon of the left cell is about $91 \mu \mathrm{m}$ from the soma. From $/ 62 /$, reproduced with permission.

axons in the Mauthner system of fish $/ 101 /$, and in the medullary pacemaker nucleus of weakly electric fish $/ 22 /$, a structure in which the local circuitry does not utilize chemical synapses. Interestingly, the medullary pacemaker nucleus functions to generate a highly coherent and precisely regulated very fast (hundreds of $\mathrm{Hz}$ to $>1 \mathrm{kHz}$ ) network oscillation. Some of the individual neurons are very fast intrinsic oscillators, and the gap junctions appear to act to maintain phase-locking between the different neuronal oscillators /49,50/. Hippocampal axonal gap junctions also play a role in very fast oscillations, but by an entirely different mechanism. Rather than acting as entraining devices between intrinsic oscillators, hippocampal axonal gap junctions allow waves of activity to spread through networks of cells that need not be intrinsic oscillators. The next section will explain how this can happen. 


\section{THE GENERATION OF VERY FAST OSCILLATIONS BY AXONAL GAP JUNCTIONS: THEORY AND MODEL}

The hypothesis of axonal gap junctions grew out of a study $/ 20 /$ on very fast multicellular oscillations. The experimental evidence reviewed above indicates that axonal gap junctions do exist between hippocampal principal neurons. Nevertheless, even if one accepts the existence of axonal gap junctions, it remains to be shown how such gap junctions could be relevant to the generation of an oscillation in a population of neurons. How does one know that the gap junctions are either necessary or sufficient for very fast oscillations, and under what conditions are the very fast oscillations possible? One would like to be able to account for oscillations of the sort observed by Draguhn et al. /20/, p-ripples, with synaptic transmission blocked, and - if possible - one would like to account also for very fast oscillations seen when at least some chemical synapses are functional. Examples of the latter are fast runs of population spikes during epileptiform bursts in disinhibited hippocampal slices $/ 63,99 /$, and in vivo ripples superimposed upon physiological sharp waves $/ 10,102 /$. It turns out to be possible to account for all of these phenomena, at least in principle, and even to predict (correctly) that very fast oscillations can give rise to oscillations at lower frequencies, in the gamma range. Experiments so far are consistent with model predictions, and we are not aware of alternative models that can account for the data; nevertheless, direct experimental demonstration of some of the ideas incorporated into the model is extraordinarily hard, for technical reasons recording from axons is difficult, and recording from directly coupled axons may be impossible. This implies that the somewhat difficult and abstract ideas in the model need to be understood in depth, as experimental tests of many aspects of the model will have to be indirect.

Neither pyramidal neurons, nor even their isolated axons, are known to be intrinsic oscillators at frequencies of $200 \mathrm{~Hz}$. Given that the axons are not intrinsic oscillators, it is therefore unlikely that gap junctions are behaving functionally in the same way as gap junctions in the medullary pacemaker nuclues of the weakly electric fish. In this latter case, gap junctions appear to act by coupling, and phase-locking, intrinsic oscillators. It appears that the mechanism of gap junction-mediated very fast oscillations, in the hippocampus, must involve some new principles.

We now review two of the experimental clues suggesting a set of assumptions that underlie a new type of population model, a model that depends on the ability of axons to be excited by phasic stimuli and to be capable of firing at high rates, but that does not depend on intrinsic oscillatory properties:

Clue 1: During p-ripples (Fig. 2), there are many spikelets and antidromic spikes in the soma. Hence, at least some axons are firing rapidly, even at the frequency of the p-ripple itself.

Clue 2: While it is not possible to measure membrane potential at the coupling site in a "post-gap junctional axon", this site being up to about $120 \mu \mathrm{m}$ from the soma, it must be the case that the potential at the coupling site is greater than the potential at the soma. This is so because of the flaring of the axonal initial segment, the low density of $\mathrm{Na}^{+}$conductance on the soma/dendrites, and the impedance load imposed by the somal dendrites on an antidromically progressing spike or spikelet. In simulations (e.g. Fig. 5), the membrane event at the coupling site - when the "pre" axon fires - is usually a full action potential, even when only a $\sim 2 \mathrm{mV}$ spikelet occurs at the soma. In some cases, however, the simulated potential at the coupling site is in the $15-20 \mathrm{mV}$ range (e.g. Fig. 8 of $/ 62 /$ ). Even in such a case, however, this "partial spike" is expected to grow rapidly into a full spike with distal (if not with proximal) propagation.

These two clues suggest the following class of models, based on a simple set of postulates:

Postulate 1: Principal cell axons are interconnected by gap junctions located at roughly the same distance from the somata. Data available so far are consistent with this. 
Postulate 2: Spontaneous "ectopic" action potentials occur in axons, from time to time. These ectopic spikes are presumed to arise at some site in the axon which is distal to the gap junction, perhaps in presynaptic terminals. Ectopic axonal spikes occur in $4 \mathrm{AP} / 3,80,88 /$; and also after tetanic stimulation of the hippocampal slice that is sufficient to lead to delayed ictal discharges $/ 69,70 /$. In the latter case, ectopic spikes recorded in CA3 pyramidal cells appear to arise in Schaffer collaterals, and so could possibly originate in presynaptic terminals. It is of interest that glutamate receptors, particularly kainate receptors, enhance the excitability of certain axons, including those of dentate gyrus granule cells 137,14,64,60,61/. (Probably, spontaneous somatic action potentials would do as well, but - due to the lower density of $\mathrm{Na}^{+}$channels on the soma than on the axon, ectopic axonal spikes would seem more likely to occur, especially in low $\left[\mathrm{Ca}^{2+}\right]_{0}$ conditions.)

Postulate 3: Ectopic spikes propagate antidromically to axonal gap junction sites, and are able to induce action potentials in electrically coupled axons with non-zero probability (see Clue 2 above).

Postulate 4: Very fast neuronal population oscillations are generated in networks of electrically coupled axons, without an essential contribution from the soma/ dendrites. The axonal network activity propagates antidromically to the somata, whence it may be recorded, but the axonal network activity can persist on its own - "autonomously". Nevertheless, somatic firing or bursting, if it occurs, can, in turn, influence the axonal activity.

Direct evidence for Postulate 4 does not exist, although the experimental evidence also does not contradict this postulate. Indirect evidence is consistent, as discussed below. The postulate works in network simulations and, in addition, this postulate allows for considerable simplification in understanding the physical principles that appear to underlie very fast network oscillations: with this postulate, one can construct highly simplified models that omit somata and dendrites, and contain only small bits of axon electrically coupled to each other. Such models are able to produce network oscillations with many of the observed experimental features.

How can one examine whether the above postulates are logically consistent and do indeed lead to population oscillations? To achieve this, we worked in stages. First was the construction of a network model that used detailed multicompartmental neurons (e.g. as in /85/); such models were already available, using neurons with sections of axon, and required modification only in the addition of the requisite gap junctions. Once it was known that the detailed model generates network activity resembling experiment, for appropriate parameter choices, it was then possible to construct a "reduced" (greatly simplified) model, that highlights the basic physical principles, and that allows more refined examination of the parameter space. Even further simplifications, and some degree of mathematical analysis, are possible, as shown in the work of Lewis and Rinzel /42/.

In either sort of model, detailed or reduced, what are some of the key "structural" parameters? The total number of neurons is one such parameter, but this can be estimated from the experimental preparation. The following list includes some of the most important remaining parameters, along with some preliminary comments on their physical significance:

1) How many axonal gap junctions should there be in the network, or, alternatively, how many axons does any given axon contact, on average?

We know that if each axon couples, on average. to less than one other axon, there will be no population phenomena, except perhaps in restricted subsets of neurons (this point is explained further below). Thus, there is a lower bound to the connectivity. Is there an upper bound? Here, we can at least make a guess based on dye-coupling data. Church and Baimbridge $/ 13 /$ found that, on average, a CA3 pyramidal cell was dye-coupled to 1.6 others at physiological pH, increasing to 3.2 others at $\mathrm{pH}$ 7.9. (Recall that we know that axonal 
gap junctions do allow for dye coupling - Fig. 8 although not all gap junctions do so.) Thus, 3.2 is a reasonable guess as to maximal connectivity; most of our simulations /85/ use 1.6. To put this number in context, the synaptic connectivity between CA1 pyramidal neurons has been estimated at about $1 \%$ 18/. In a population of $3,000 \mathrm{CA} 1$ pyramidal neurons, each one would be expected to receive synaptic excitation from 30 other neurons: thus, the chemical synaptic connectivity appears to be much richer than the connectivity mediated by axonal gap junctions.

\section{2) Where on the axon are the gap junctions located?}

The model pyramidal neurons that we use /79/ only possess five axonal compartments, each $75 \mu \mathrm{m}$ long. Assuming that homologous compartments are to be coupled, there are then only five choices. Most of the initial simulations were performed with junctions between the penultimate axonal compartments. The data of Schmitz et al. /62/ (e.g. Fig. 4 of this review) were most readily replicated with a more proximal gap junction, just distal to the axon initial segment, i.e. about $100 \mu \mathrm{m}$ from the soma and morphological studies (Fig. 5) turned out to be consistent with this, at least for CA1. Some network simulations have also been done with the gap junction located in the more proximal site.

\section{3) What spatial constraints are present on the connectivity?}

Obviously, if axonal gap junctions are located at, say, $x \mu \mathrm{m}$ from the soma, then two coupled neurons can not have somata more than $2 x \mu \mathrm{m}$ apart. In the actual hippocampus, it may even be that a still tighter constraint applies. In our network models, the position of neurons is specified in terms of somatic position. It is therefore necessary to define which neurons are allowed to connect to which. We usually impose a constraint such that the somata must be within $200 \mu \mathrm{m}$, and do not allow for the possibility that connection probability could be dependent on intersomatic distance, even when both somata are relatively close: thus, if the somata are close enough, connection probability is constant, and independent of distance.

\section{4) What is the conductance of the axonal gap junction?}

Unfortunately, there does not appear to be a method for determining this quantity directly: presumably, the requisite experiment would require placing an electrode on two axons simultaneously, one on either side of the gap junction. Determining this quantity indirectly, for example by measuring the DC coupling ratio between two somata whose axons share a gap junction, would appear to be quite difficult. First, we have not succeeded in identifying such a pair in dual simultaneous recordings, perhaps because the connectivity is so low (see above); others, however, have reported such coupling $145,46 /$. Second, the DC coupling ratio produced by an axonal gap junction is expected to be small, given the high input resistance of the axons; it presumably would be hard to measure the coupling ratio accurately, and may even be impossible to determine at all. Finally, one would need accurate fills of both cells, in addition to careful estimates of the passive electrotonic parameters, in order to calculate the gap junction resistance from the coupling ratio. Measuring membrane resistivity and internal resistivity of the axon would appear to be difficult.

Using network models empirically, however, we found that the conductance per se of the axonal gap junction is not what matters functionally. Rather, what matters is whether a spike can cross the junction from one axon to the other. If the gap junction never permits such crossing, then interesting network behavior does not occur amongst the axons. If the gap junction does permit such crossing, then rich network behavior can occur. What the exact value of the necessary conductance is, in Siemens, is difficult to know experimentally, but in a simulation the necessary conductance can readily be determined by trial and error $(\sim 2.5 \mathrm{nS})$.

Another quantity that is important in the model is the time it takes for a spike in one axon to induce a spike in an electrically coupled axon. This time is expected to depend, at least somewhat, on the gap junction conductance. Nevertheless, it is difficult to determine this quantity directly. MacVicar and Dudek /46/ provide what we interpret as an indirect estimate: the shift in latency between a directly evoked antidromic spike (in a dentate granule cell), 
and a spikelet evoked in the same neuron by a weaker axonal stimulus. This delay is about $0.3 \mathrm{~ms}$, and we suggest that it corresponds to the time it takes for a spike to cross from a directly stimulated and firing axon, into an axon that is not directly stimulated (as in Fig. 3). The "crossing time", along with network topology, is a major determinant (in models) of the period of very fast oscillations in axonal networks.

\section{5) Does the axonal gap junction have special properties such as rectification?}

Again, this is difficult to determine experimentally. One can only say that the junction conducts if the voltage on one side of it is strongly depolarized (i.e. firing an action potential). Furthermore, the molecular nature of the constituent connexin is not known. It appears that axonal gap junctions do not consist of connexin-36, at least not exclusively: p-ripples in connexin-36 knockout mice are indistinguishable from p-ripples in wild-type mice $/ 33 /$. In simulations, we make the simplest assumptions concerning the properties of axonal gap junctions: that they are linear, voltageindependent, and non-rectifying.

6) What are the statistical properties of the processes that generate spontaneous ectopic axonal action potentials? For example, do ectopic spikes in different axons occur statistically independently?

So far as we are aware, there is no information on this issue. In models, we assume that ectopic spike generation occurs in each axon according to a Poisson process (the simplest assumption), that the processes are independent between different axons, and that the Poisson parameters are all identical. The Poisson parameter, i.e. the mean rate at which ectopics occur per axon, is one of the parameters that determines the collective behavior of the axonal network.

Before we consider the dynamic behavior of a network of neurons with gap junctionally coupled axons, it may be helpful to consider the geometric properties of such a network, in a somewhat abstract representation of the network (Fig. 9). In Figure 9, each circle represents a neuron (alter-
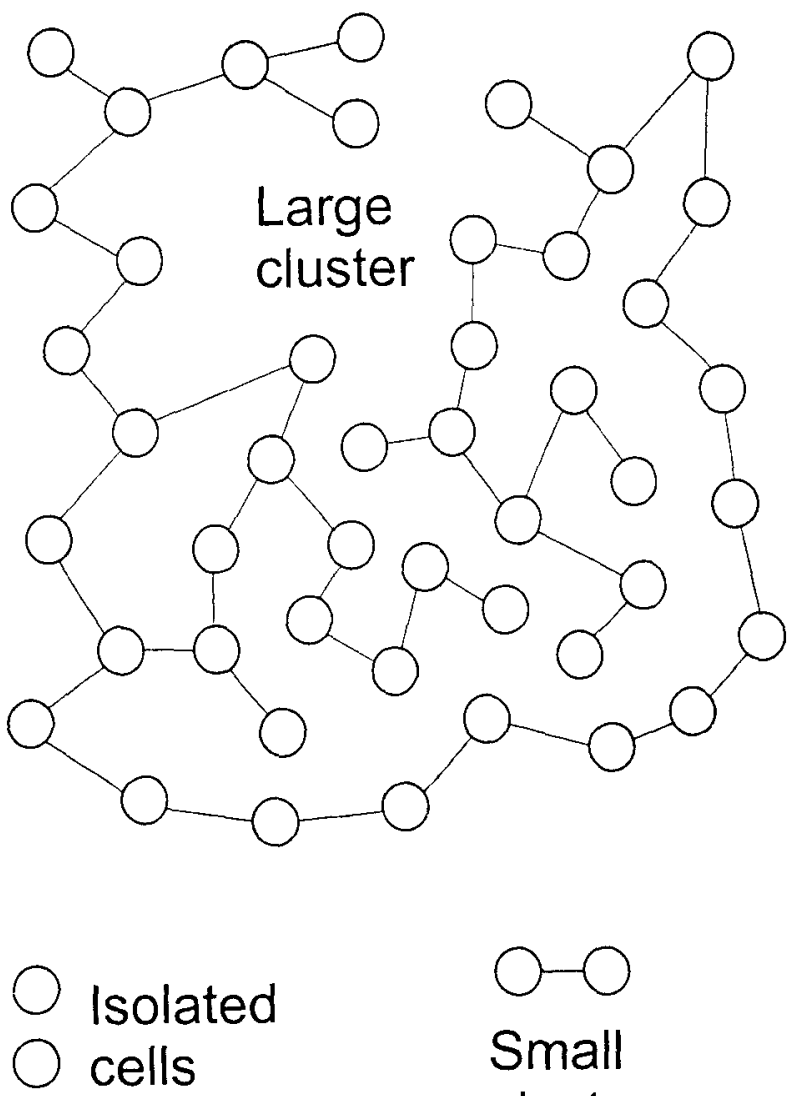

Small clusters

Fig. 9: The structure of a "random graph" $/ 23 /$ in which there are a sufficient number of connections. Each circle represents a "node" in the random graph, and each line, connecting two circles, represents a branch. If there is, on average, more than one branch emerging from each node, then (with probability approaching 1 as the size of the graph becomes indefinitely large), the graph will be arranged into a) a single "large cluster" of interconnected nodes, whose size is of the same order as the size of the whole graph; b) various "small clusters", whose size is small, compared to the whole graph; c) various isolated nodes that do not connect to anything. One can think of each node as representing a neuron, or alternatively as an axon; and each branch can be taken to represent a gap junction. Collective oscillations depending on gap junctions will be developed on the large cluster. The size of the large cluster, relative to the whole system, increases with the number of branches, but is surprisingly big, even for an extremely small connectivity $/ 85 /$. 
natively an axon), and the straight line segments represent gap junctions; the gap junctions are presumed to have been placed randomly (actually, in a biological network, the gap junctions cannot be placed truly randomly - as faraway cells cannot connect - but this appears not to make a big difference). After the gap junctions have been placed, is it possible to make any statements about the resultant network? In a classic paper, Erdös and Rényi /23/ considered problems of this general sort, in networks of size that became arbitrarily large. (The mathematical name for a network such as we have described is a "random graph".) One result that is important for our purposes says, in effect, this: if each cell connects, on average, to less than one other, then there is no "global" network at all; instead, there will be isolated cells, and a number of small "mini-networks" (by "small", we mean "small relative to size of the whole system"). In contrast, if each cell is connected to more than one other cell, then the situation is completely different. In this case, there will be exactly one "large cluster", where "large" means roughly "having a size comparable to the number of cells in the whole system", and "cluster" means (a) a path exists between any two cells in the "cluster", and (b) adding one more cell destroys property (a). The cells which are not in the large cluster are either isolated or else lie in "small clusters". Cells that are isolated or that lie in small clusters will, of course, fail to participate in network behavior: the network will be dominated by what is happening amongst the interconnected cells of the large cluster provided, of course, that chemical synapses are blocked.

Erdös and Rényi even provided an analytical formula for the size of the large cluster as a function of the connectivity; the resultant curve is reproduced in $/ 85 /$. To be noted is the fact that even small connectivities give rise to surprisingly extensive large clusters. For example, with each cell connecting to 1.6 others on average, the large cluster is more than $60 \%$ of the entire system. (We choose the 1.6 example because we believe it to be biologically reasonable.) What is not so obvious, but is nevertheless true, is that the large cluster can be extensive, and also be sparse, at the same time. That is, the large cluster may contain many neurons, and yet one still has to cross many gap junctions to get from one neuron to another, on average. For example, in one sample network with 3,072 cells, each connected to an average of 1.6 others, the large cluster contained 1,990 cells (about $65 \%$ of the system); but the average number of gap junctions crossed between a random pair of

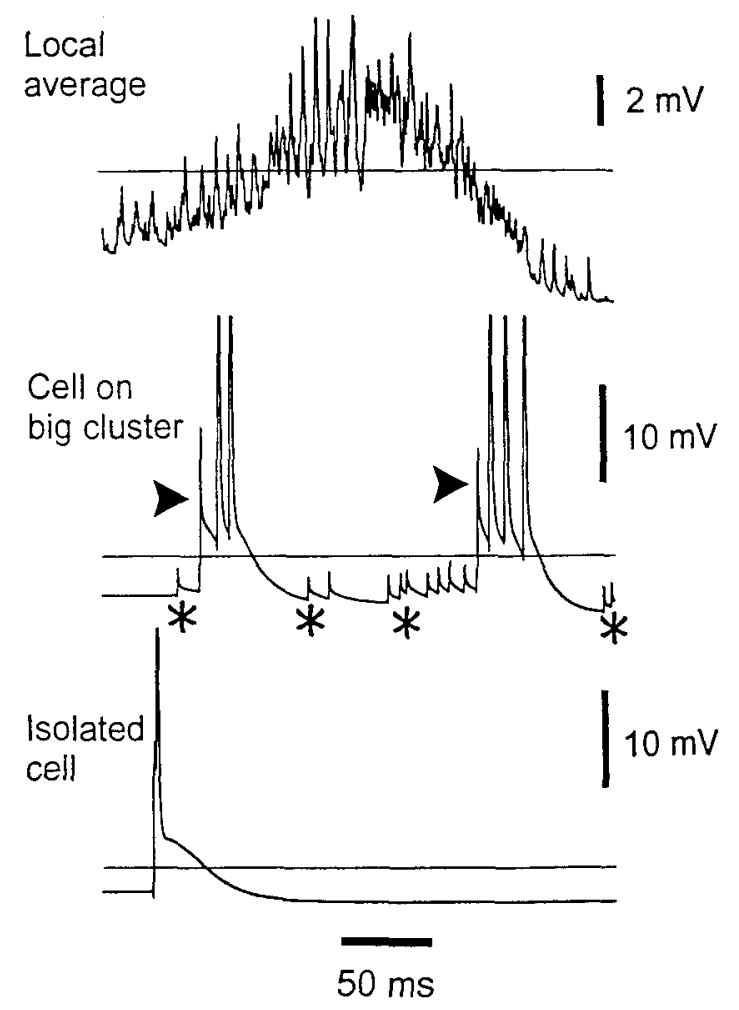

Fig. 10: Simulation of a very fast network oscillation in a population of 3,072 model pyramidal neurons, sparsely interconnected by axonal gap junctions, without chemical synapses. There was a background of randomly occurring, spontaneous "ectopic" spikes in the axons (average of 2 per second per axon), and the axonal gap junction conductance was large enough that an action potential could cross from axon to axon. The top trace, an average of the somatic potentials of 224 neurons, shows a very high frequency oscillation, with a mean underlying depolarization. The soma of a cell lying on the large cluster (see Fig. 9) illustrates a mixture of action potentials (truncated), partial spikes (arrowheads), and spikelets $\left(^{*}\right)$. Isolated cells (lower trace) fire rarely. This cell exhibits a notch on the upstroke of its antidromic action potential (cf. Figs. 2, 5). Same simulation as in Fig. 12 of $/ 85 /$. 
cells in the large cluster was $>17 / 85 /$. This sparseness of the connectivity is critical in determining the properties of oscillations generated in this type of network.

Let us consider now an example of a simulation in a network of 3,072 pyramidal neurons, interconnected by axonal gap junctions, but without chemical synapses, in which action potentials can cross from axon to axon. Ectopic spikes were triggered at an average rate of 2 per second per axon. From this simulation, and many similar ones, we see the following:

1. There is a population oscillation (about $140 \mathrm{~Hz}$ ) recognizable in the average potential of nearby somata in many cells (upper trace).

2. The oscillation begins even when cell somata are not firing - in this and similar simulations, the axonal network alone can generate a population oscillation on its own, provided that cell somata and initial segments are not so shunted as to prevent spikes from propagating axon-to-axon.

3. Cells in the large cluster (e.g. middle trace) participate in the population, with antidromic spikes, partial spikes (arrowheads) and spikelets $\left({ }^{*}\right)$ - all of these resemble events recorded experimentally $/ 20,62 \%$. The potentials in the illustrated cell should be compared with the experimental recording shown in Figure 1.

4. As expected, cells not in the large cluster (e.g. bottom trace) do not participate in the population activity.

(Lest the reader think that the oscillation results from re-entry - a spike passing from axon to axon over gap junctions in a cycle, until it returns to reexcite the original axon - we note that similar oscillations occur in networks without any cycles 185/. Re-entry is not required and does not appear to be important in very fast oscillations in the hippocampus.)

We must now consider how the axonal plexus generates a population oscillation, and what factors determine the amplitude and frequency. (Actually, we shall see that the population "rhythm" is not, strictly speaking, an oscillation; it might more accurately be described as a series of waves, having roughly equal inter-wave interval.) Analysis of this issue is facilitated by consideration of a reduced model, a so-called cellular automaton model /85/. Here are the assumptions which determine how such a model can be constructed:

1. Time is quantized into discrete steps. We can suppose that each step is $0.25 \mathrm{~ms}$, the approximate time it takes for a spike to cross from axon to axon.

2. Each axon can exist in any of three states: "on" (i.e. firing), indicated by $\bullet$ in Figure 11; "refractory" (i.e. fired recently, and unable to be re-excited), indicated by $\otimes$ in Figure 11; and "resting" (i.e. able to be triggered to fire), indicated by $\mathrm{O}$ in Figure 11.

3. Network topology can be chosen at will: for example, a random graph of the sort used in Figure 10; or a "tree", used for illustrative purposes in Figure 11.

4. There is a fixed, predetermined probability, $p$, that, during any time step, a resting axon will fire spontaneously, i.e. independently of whether that axon's neighbors are (or have been) firing.

5. The network as a whole evolves in this way: if an axon is resting, it fires with probability $p$ as a spontaneous event; if an axon is resting and any of its immediate neighbors has just fired, then that axon fires as well, with probability 1 . If there is no spontaneous firing, and none of the neighbors has just fired, then the axon remains at rest. If an axon has just fired, then it becomes refractory for two time steps, after which it enters the resting state.

The above dynamics approximate this simplified biological situation: the most relevant part of the axon is that portion near to, and containing, the gap junction, and we presume that this part can be described as a single compartment; detailed kinetic processes in the membrane can be ignored - the axon either fires or it does not; post-spike membrane processes can be approximated as shortduration absolute refractoriness, and slower membrane processes can be ignored; spikes cross gap junctions faithfully.

Figure 11 illustrates how a wave of activity can develop if the entire network is at rest, and one axon (for simplicity, chosen to be the "root" of the tree) fires spontaneously (Fig. 11-1). Firing then spreads outward, step by step, so that after $k$ steps, 
1)

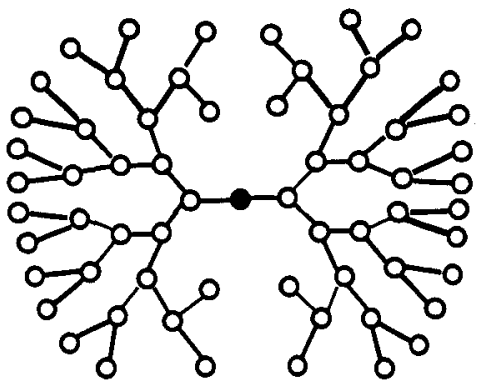

2)

3)
4)

5)

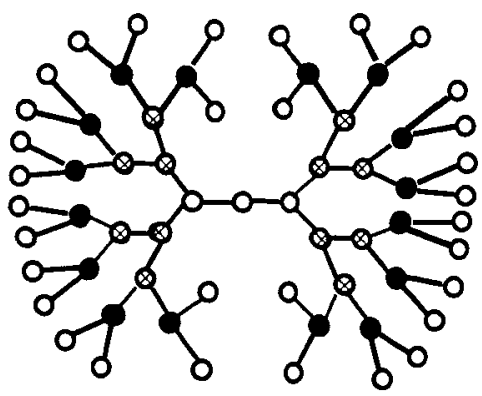

6)
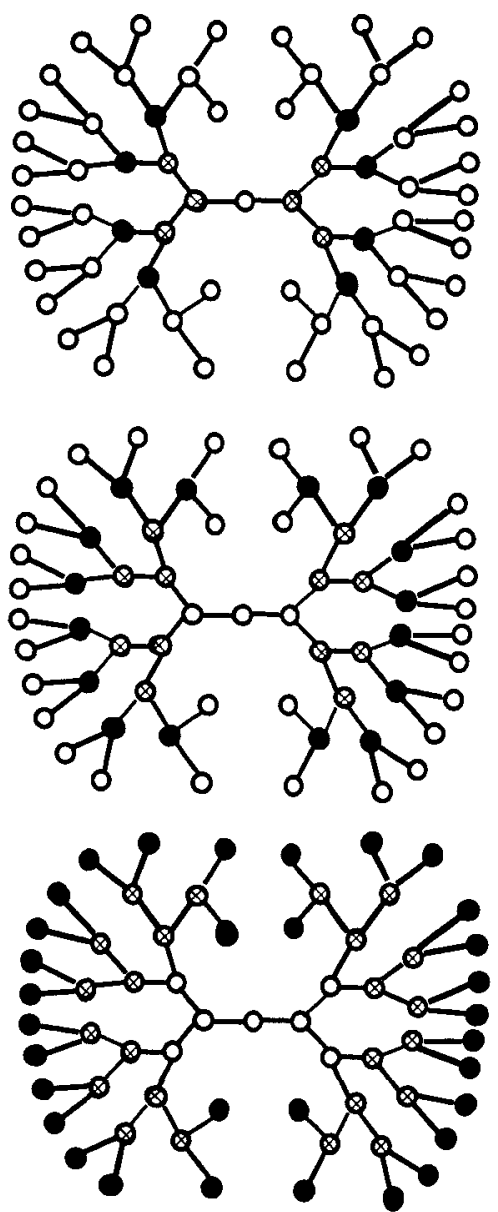

Fig. 11: Spread of activity through a network, illustrating some of the factors that determine the period. The network shown is a binary tree, simpler than a random graph. We suppose that an action potential lasts one time step, and spreads to its non-refractory neighbors in one time step; and that refractoriness (inability to fire) lasts two time steps. Cells that are firing are shown by $\bullet$, those at rest and excitable by $O$, and those that are refractory by $\otimes$. 1) Spontaneous action potential occurs at the root of the tree. 2) The action potential spreads to two neighbors, and the root becomes refractory. 3-6) Activity spreads as a wave, leaving a wake of refractoriness "inside" the wave. The time to the peak of activity corresponds to the "height" of the tree. See text for further details.

$2^{k}$ axons are firing. Behind the expanding front of firing cells is a "wake" of refractory cells. When the wave reaches the outermost reaches of the tree, it simply stops, as the wake of refactoriness prevents further (backward) spread. Thus, a single spontaneous event leads to an exponentially growing wave of activity, whose duration is the number of levels in the tree.

A single wave of activity, however, is not an oscillation. Obviously, multiple waves are needed for there to be an oscillation. We also see that, at least in a tree-network, each waves grows and then dies - thus, to have multiple waves, there must be multiple, independent, spontaneous initiating events.

The critical insight that helps in understanding this more complicated situation is as follows: one can think not just of a single underlying network, the "anatomical" network, defined by which axons are electrically coupled to which other axons. Rather, one should think of a series of "functional" networks, that represent the anatomical network, as its structure is redefined and modified by ongoing activity. Why do this? The point of picturing the network is to be able to visualize the pattern of 
firing cells, and to be able to predict how firing will spread. If the whole system is at rest, except for one active cell, then the spread of activity is determined precisely by the connections which are present, by the anatomical structure. On the other hand, if there is activity, the spread of activity is not solely determined by anatomy: this is so because spread cannot occur to cells that are already firing, or that are refractory. "Anatomical" connections are present which have become non-functional. The easiest way to visualize the "functional" network is thus as the original anatomical network, from which have been removed all axons that are either firing or are refractory. Of course, once refractoriness has worn off, then axons - along with their connections - are to be re-inserted into the functional network. Picturing the system in this way allows one to understand, at least qualitatively, what will happen when there are multiple spontaneous action potentials. (For further analysis, please see Lewis and Rinzel /42/.)

In order to give a specific example, consider the functional network in Figure 11-4. If we remove the firing cells and the refractory cells, what is left? There will cells outside the advancing wave; these consist of 16 little trees, consisting of three cells each, 48 cells in all. In addition, there is the single cell inside the wave, namely the cell at the center of the network. A spontaneous event occurring in one of the little trees can grow very little before it collides with. and is absorbed by the advancing wave (remember that waves cannot pass through each other, because of refractoriness). A spontaneous event in the center can, however, generate another wave which will spread out behind the first one. But, if the spontaneous events occur randomly, and are not excessively frequent, by far the most likely place for a spontaneous event will be outside the wave - where it will have little effect.

Consider the functional network in Figure 11-5. The majority of cells ( 32 of them) are isolated ones on the outer fringes. Spontaneous events in any of these cells cannot propagate. There are three cells in the interior; spontaneous events in any of these cells can generate waves that follow the original wave.

Thus, in the early and middle stages of the wave, further spontaneous events are most likely to occur outside the wave; the effects will be either limited propagation, or perhaps a small wave that will eventually coalesce with the original. But as the original wave nears the end of its "life-span", it becomes increasingly probable that a new spontaneous event occurs on the inside, and leads to another wave. In this case, population activity can be organized into a series of waves. One sees that the periods between waves will vary around some mean, because spontaneous action potential generation is stochastic. Furthermore, the waves will not all be identical, because the pattern of secondary, coalescing smaller waves (originating outside the big waves) will constantly be changing. Finally, one sees that - if an oscillation is to occur then the rate of spontaneous events can be neither too small nor too large. Suppose, for example, that spontaneous events occur at some vanishingly small rate. Then there will be long, and variable, silent periods between the waves, which will, in effect, become isolated from each other. Suppose, on the other hand, that spontaneous events occur extremely often, often enough that spontaneous events occur on the interior of a wave even as it is just beginning to propagate. In this case, population activity cannot organize into a series of waves at all.

When the activity is organized into a series of waves, at intermediate values of the spontaneous firing rate, one sees that the period of the oscillation is determined by how long it takes for a wave to spread through the network. This is a topological property of the network, and is independent of the refractory time (assuming the refractory time is short). That is, the time for signals to spread through the network will, in general, be much longer than the time it takes for any one cell to overcome its refractoriness. One can estimate the period of the oscillation as a product of two quantities:

period $=$ faverage number of gap junctions that must be crossed to get from the site of a spontaneous event to the "ends" of the network\} $x$ the average time it takes for a spike to cross a gap junction!.

Here is one example of the use of this estimate in Eq. 1. We examined a network of 3,072 pyramidal 
cells (a reasonable estimate for the number of neurons in some large fraction of $\mathrm{CA} 1$ or $\mathrm{CA} 3$ in vitro), in which each axon was connected to 1.6 others, on average. The first quantity on the right side of Eq. 1 was $>17$ : we know this because the "mean path length", the average number of links between a random pair of cells, was about 17; and the number of links between a random cell and the boundaries of the large cluster should be larger. We estimate the second quantity as about $0.25-0.3 \mathrm{~ms}$. The oscillation period should then be more than about 4.25-5.1 ms. The spectral peak in the network behavior was at $141 \mathrm{~Hz}$, corresponding to $7.1 \mathrm{~ms}$.

This type of cellular automaton model, with many more cells than in the simple example of Figure 11, has been useful for understanding the effects of several of the key parameters of the oscillation $/ 85 /$. Consider, for example, the network connectivity in a case in which network size and other parameters are held constant, using Figure 11 as a mental schema. Suppose first of all that the connectivity is extremely small, just above one connection per cell on average. This means that the large cluster will not be all that large - the extent of population activity must be limited. Furthermore, a spontaneous event will spread through the large cluster very slowly indeed - the wave will take a long while, and the peak amplitude will be relatively small. At the other extreme, suppose the connectivity is so high that every cell connects directly to every other cell. In this case, a spontaneous event anywhere spreads to the whole system in one time step: network activity is now dominated by intrinsic refractoriness, rather than by the length of paths in the system. As noted above, very fast population oscillations that look like biological recordings occur with connectivities that are between these two extremes.

\section{THE EFFECTS OF AXONAL NETWORK VERY FAST OSCILLATIONS ON LARGER NEURONAL NETWORKS: RIPPLES}

Once very fast network oscillations occur in the plexus of pyramidal cell axons, as does indeed appear to take place, one next needs to know what effects such an oscillation can have on the neuronal network as a whole. Such effects can be complicated, but can be analyzed in stages.
INT. DENDRITES

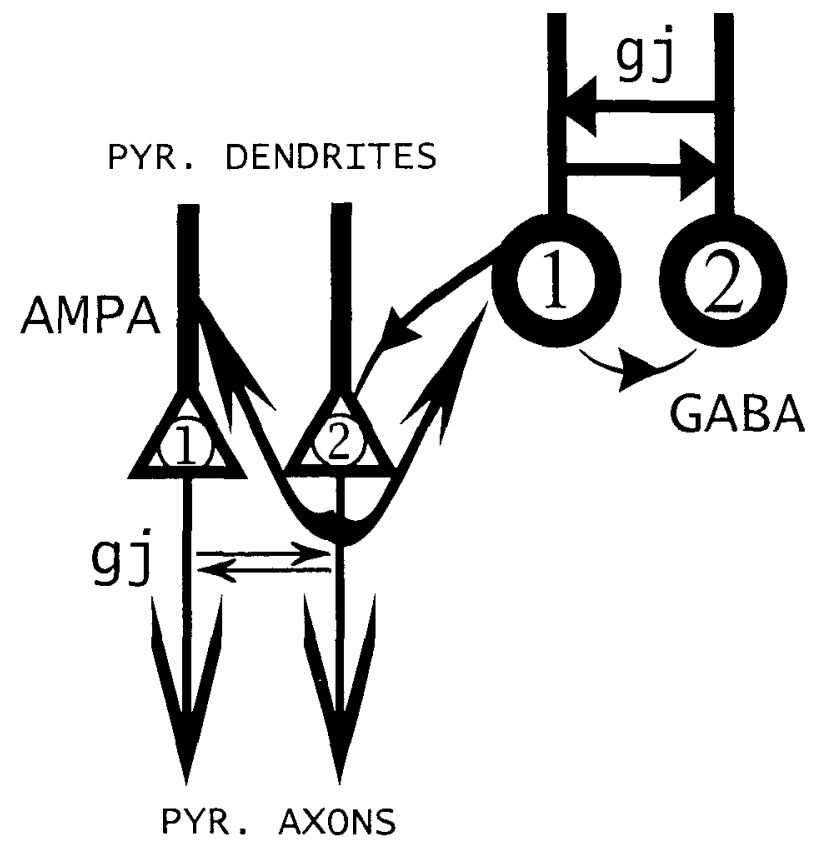

Fig. 12: Local circuit interactions in the hippocampus, including synaptic interconnections (excitatory and inhibitory, within and between the respective cell populations), and gap junctions (between principal cell axons, between certain interneuron dendrites, and perhaps at other locations).

As Figure 12 indicates, there are two major considerations. First, pyramidal cell axonal plexus activity can propagate both antidromically and orthodromically, the latter to pyramidal cells as well as to interneurons. Second, there will be an interplay between what the pyramidal axons are doing with other sorts of interactions in the system, including interactions mediated by chemical synapses and interactions mediated by gap junctions between interneurons. Many new parameters are introduced into the modeling of such a complex network, including the synaptic conductance values and connectivities, and the sort of background stimulation that is delivered to the constituent neurons. The system schematically illustrated in Figure 12 has not yet been fully analyzed, but information is available on some of the components. 
Principal cell soma/dendrites

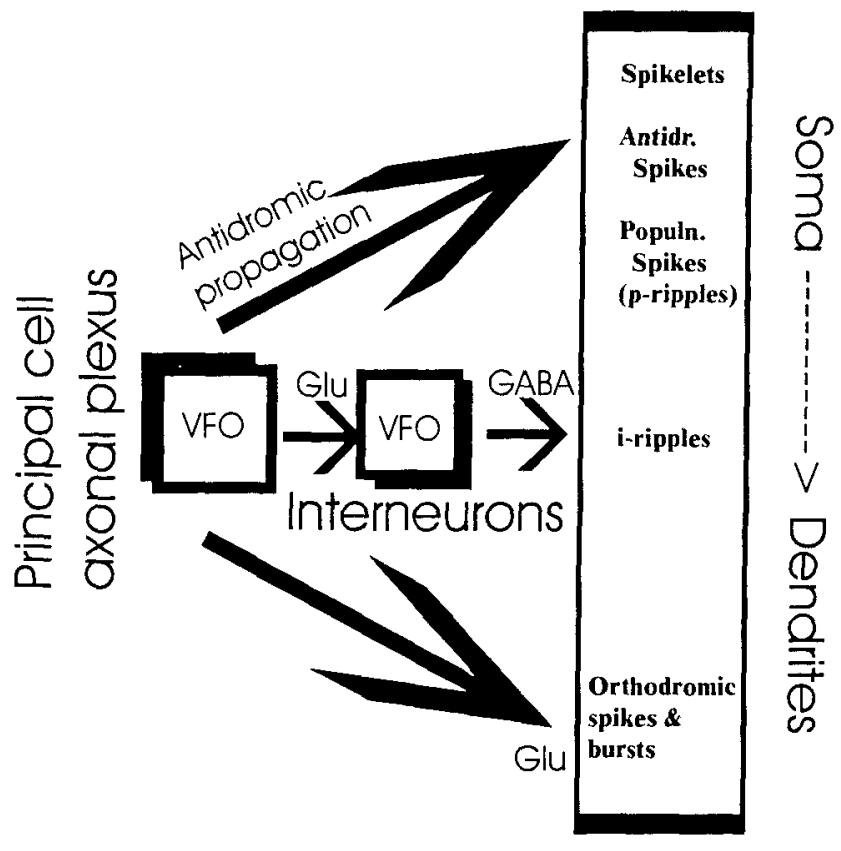

Fig. 13: Very fast oscillations, generated in the axonal plexus of principal neurons, can influence the larger network in different ways, depending on how activity is propagated. Antidromic propagation in principal cell sonata leads to spikelets and antidromic spikes; if this occurs in enough neurons simultaneously, p-ripples (high frequency small population spikes) may be recorded as field potentials. Orthodromic propagation to interneuron populations can lead to very fast, coherent firing of interneurons, generating rhythmic very fast IPSPS in principal neurons, i-ripples, as is believed to happen during in vivo sharp waves. Orthodromic propagation to principal neuron dendrites could, in principle, drive extra action potentials and/or bursts.

Figure 13 shows some of the ways that the pyramidal cell axonal plexus can influence pyramidal cells themselves, using the simplifying assumption that influences operate exclusively in one direction: from the pyramidal axons to other elements in the system, but not vice versa. Thus, we have already seen that very fast oscillations (VFO) in the axonal network can propagate antidromically into pyramidal cell somata, inducing spikelets and antidromic spikes in individual neurons, and producing p-ripples at the population level, recordable with an extracellular electrode. In addition, axonal activity can, in principle, propagate orthodromically to pyramidal cell dendrites, and induce dendritic bursts; we are not aware, however, of direct evidence that this actually happens. It is true, at least in simulations $/ 85 /$, that recurrent synaptic excitation and axonal gap junctions can work together, producing epileptiform bursts with a superimposed VFO consisting of population spikes. Activity similar to this is recorded experimentally during epileptiform field potentials $/ 63,99 /$.

An indirect means for pyramidal cell axonal VFO to influence pyramidal cell soma/dendrites is shown in the middle of Figure 13. In this case, the population output of the axonal plexus, consisting of fast, organized waves of axonal firing, projects orthodromically to nearby interneurons. Interneurons are in many cases capable of firing at high frequencies, and EPSPs onto at least some interneurons are extremely fast $/ 27,30 /$. Thus, the axonal output can, in principle, induce organized firing of populations of interneurons at, say, $200 \mathrm{~Hz}$. The interneuronal activity in turn, induces fast runs of population IPSPs in the pyramidal cells - so-called i-ripples.

This proposed mechanism for i-ripples, in simulations $/ 87 /$, leads to neuronal activity that closely resembles activity recorded during in vivo ripples in the hippocampus $/ 10,102 \%$. (Somewhat similar-appearing activity has also been recorded in entorhinal cortex $/ 12 /$, and in the neocortex $/ 35,36$, 29/. As in the hippocampus, i-ripples tend to occur in the neocortex when principal cells are depolarized /29/.) What our model proposes is that principal cells are usually somewhat hyperpolarized, so that the proximal axons and nearby axonal gap junctions - located not too far from the somata - do not allow for passage of action potentials from axon to axon. During a physiological sharp wave in the hippocampus (or during the depolarizing phase of the slow neocortical sleep rhythm), the pyramidal cells depolarize so that axonal gap junctions become functional. The axonal plexus then can generate VFO, and events proceed as in the middle part of Figure 13. Figure 14 demonstrates that this model produces cellular potentials that look quite realistic (cf, e.g., /102/). 

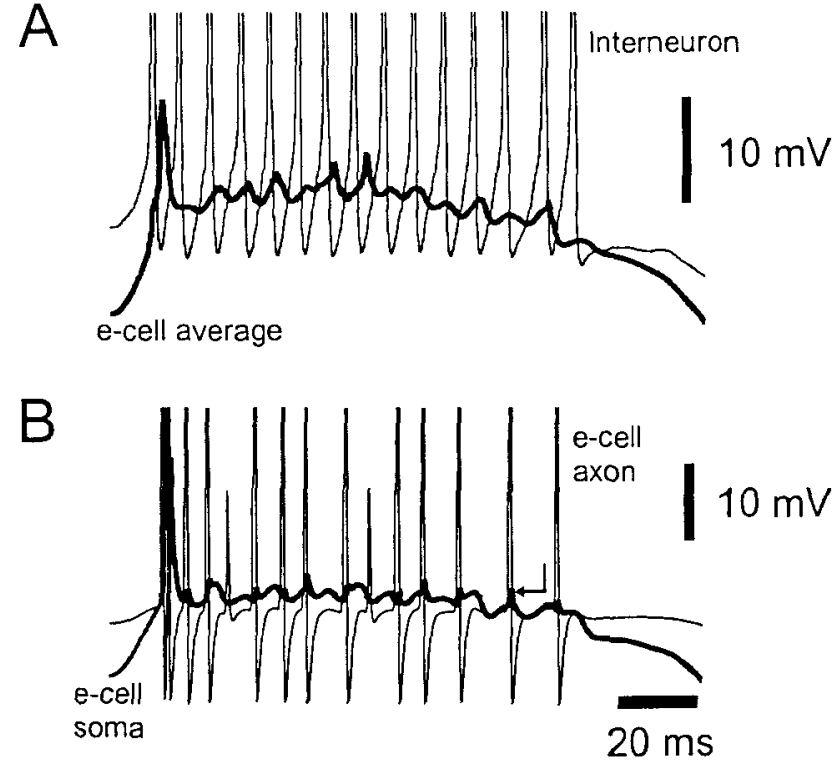

Fig. 14: Simulated i-ripples in a network of 3,072 principal neurons (e-cells) and 384 interneurons, intended to model how in vivo ripples $/ 10,102 /$ might occur. A very fast oscillation occurs in the pyramidal cell axonal plexus, one axon of which is shown in B. This drives interneurons, one of which is shown in $\mathbf{A}$, forcing them to fire at high rates. The effect on pyramidal cells is to produce a very fast series of IPSPS, with rare action potentials. Such action potentials as do occur in this model are antidromic. From $/ 87 /$, reproduced with permission. (C2000, Society for Neuroscience.

Our model accounts for two in vivo experimental observations. One is that in vivo ripples, in both the hippocampus and neocortex $129,102 /$ disappear when halothane (which blocks gap junctions) is used as the anesthetic, even though in the case of the hippocampus - sharp waves persist. Second, our model accounts for the phase shift in the ripple when the $\mathrm{Cl}^{-}$reversal potential is altered in a depolarizing direction $/ 87,102 /$.

An interesting side-light of the ripple model is this: the model replicates the experimental observation that pyramidal cells fire rarely during in vivo ripples. In the model, however, all of those pyramidal cell spikes which do occur are antidromic. So far as we are aware, it is not possible to determine from the in vivo data whether the pyramidal cell spikes are antidromic. If action potentials during the ripple are initiated primarily in axons, it is not easy to see what role ripples might play in information processing.

\section{VERY FAST OSCILLATIONS AND GAMMA (30-70 HZ) OSCILLATIONS}

Very fast oscillations ( $>70 \mathrm{~Hz}$ or so), produced in the axonal plexus of hippocampal pyramidal neurons, appear to be important in the generation of population gamma oscillations, at least gamma that is induced in hippocampal slices by certain drugs, such as carbachol /24/ and kainate - so-called "pharmacological" gamma /33/.

In order to understand why the axonal plexus might play a role in pharmacological gamma, it is first necessary to review some experimental facts about other sorts of in vitro gamma. First, there is "ING", inhibitory network gamma, evoked by tonic depolarization of pharmacologically isolated (except for mutual GABAergic interactions) networks of interneurons $194,81 /$; the tonic depolarization can be induced by a number of means, including activation of metabotropic glutamate receptors with glutamate itself, ACDP, or DHPG; or by puffing hypertonic $\mathrm{K}^{+}$solution $/ 41,75,76 /$. Second, gamma oscillations can be evoked in CA1 by tetanic stimulation $182,95,97 /$. In this case as well, interneurons (pyramidal cells also) are strongly depolarized. In simulations, interneurons that are tonically firing, or that are phasically excited in rhythmical fashion by pyramidal cells $/ 83 /$, shape the gamma oscillation by IPSPS, either in pyramidal cells, or in other interneurons, or both, depending on circumstances.

In pharmacological gamma, however, interneurons - at least in s. pyramidale - are depolarized by only a few $\mathrm{mV} / 86 /$. The conditions in this oscillation are therefore different from the usual form of ING. Furthermore, the gamma oscillation requires AMPA receptors, and it is AMPA receptors on interneurons that are the ones that force the interneurons to fire (it seems unlikely that AMPA receptors on pyramidal cells play a critical role in the oscillation). The problem is that pyramidal cells - at least the pyramidal cell somata - fire both rarely (e.g. at $2 \mathrm{~Hz}$ or so), and intermittently, during pharmacological gamma. This creates an apparent paradox. 
One clue to the solution of the paradox comes from our model of ripples /87/: autonomous activity in the pyramidal cell axonal plexus can excite the interneurons, whether or not pyramidal cell somata are firing. But even if pyramidal cell axonal firing is "driving" the interneurons, why would the network oscillation appear at gamma frequency? A possible answer to this question, one that works quite well in network simulations, is that synaptic inhibition of pyramidal cells takes place not only on somata and dendrites, but also on axon initial segments $/ 40 /$ Given that axonal gap junctions - at least according to the limited data available so far are within about $120 \mu \mathrm{m}$ of the pyramidal cell soma - then rhythmic initial segment (and also, to some extent, somatic) IPSPs would be expected to interrupt axonal plexus activity. These ideas were tested in a detailed network model that included pyramidal cells, interneurons, chemical synaptic connections, axonal gap junctions (between pyramidal cells), and spontaneous "ectopic" spikes in axons $/ 86 /$. The assumption of ectopic spikes in these simulations is especially reasonable, given that kainate directly excites axons, both of principal cells $/ 37,60,61$ /and of interneurons $/ 64 /$.

Such a detailed model works extremely well. The model produces a gamma oscillation in which, as in experiments, interneurons fire at nearly the frequency of the network oscillation, whereas pyramidal cells (somata) fire rarely and intermittently. The model also replicates known pharmacological results: the oscillation is suppressed during blockade of any of the following interactions - gap junctions, $\mathrm{GABA}_{\mathrm{A}}$ receptors, or AMPA receptors $124,86 /$. Most remarkably, the model predicts that the power spectrum of the average population behavior should contain not only a gamma peak, but also a very high frequency peak, corresponding to the axonal network oscillation. Such a high frequency peak is indeed observed experimentally (e.g. /89/). Gamma oscillations evoked by a puff of hypertonic $\mathrm{K}^{+}$also exhibit a very high frequency spectral peak, and this peak (but not the gamma peak) persists during blockade of GABA and glutamate receptors - consistent with an origin in gap junctions $/ 89 /$. Principal cell gap junctions in the model also allow a predominantly interneuronal gamma oscillation to be tightly synchronized on a
$>1 \mathrm{~mm}$ spatial scale, as is observed experimentally in CA3 $/ 86 /$.

In much of the above discussion, we have dwelled on the means by which axonal gap junctions can organize random spontaneous ectopic spikes into a network oscillation. Axonal gap junctions serve another purpose, however: as a form of amplification of spontaneous activity. Thus, under conditions in which axonal gap junctions allow spikes to pass from axon to axon, then an action potential originating in the large cluster can, in principle, force all (or nearly all) of the cells in the large cluster to fire as well. We have seen that, in the presence of enough spontaneous activity, many ectopic spikes do not propagate far (because of refractory cells blocking propagation), but it is always the case that at least some spikes can propagate. In the case of pharmacological gamma, the organization of axonal activity into a very fast oscillation is not critically important for gamma to occur: what matters is that enough axonal activity takes place so that it can tonically excite the interneurons. In principle, the gamma oscillation would therefore work without axonal gap junctions, provided only that ectopic spikes occurred at high enough frequency. Simulations are consistent with this idea. The experimental consequence is that an oscillation in the brain might be critically dependent on axonal excitability, yet not necessarily dependent on axonal gap junctions. Only when there is a simultaneous very fast oscillation present would we guess that axonal gap junctions are significant.

\section{VERY FAST OSCILLATIONS AND EPILEPTOGENESIS}

We noted above that very fast oscillations are superimposed upon epileptiform bursts in the in vitro hippocampus $163,99 /$. Is it possible that $\mathrm{VFO}$ (and hence axonal gap junctions) play a role in either initiating, or in sustaining, ictal discharges? In vitro data suggest that such a role is possible, at least under certain circumstances.

Figure 15 (data of M.A. Whittington, from /89/) illustrates field potential recordings from the $\mathrm{CAl}$ region of rat hippocampal slices. In Figure 15A, the control recording shows a gamma oscillation the 


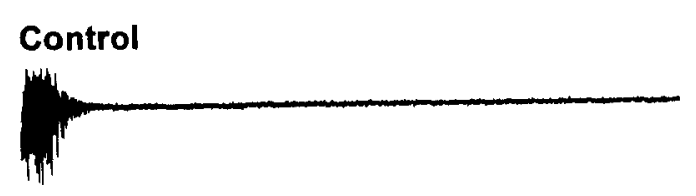

TMA $2 \mathrm{mM}$

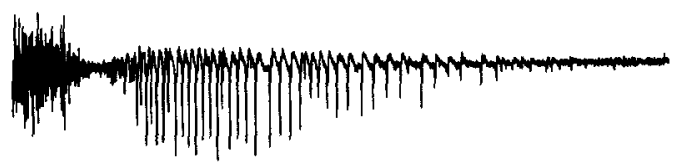

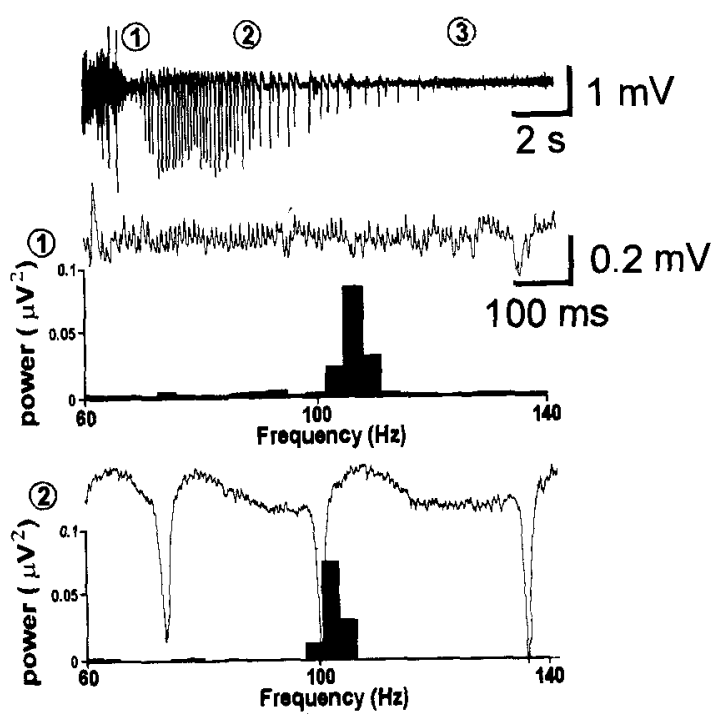

TMA + carbX $0.5 \mathrm{mM}$

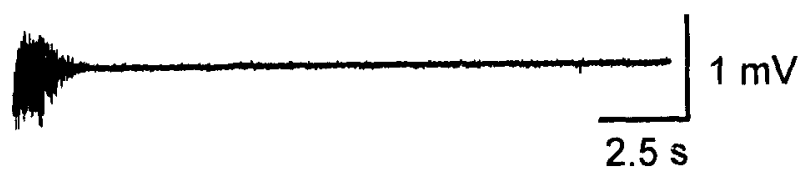

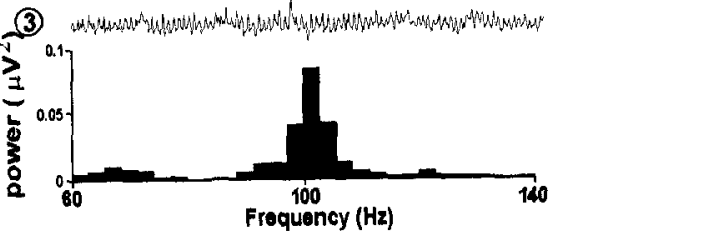

Fig. 15: In the presence of trimethylamine (TMA), tetanic stimulation of hippocampal CA1 in vitro leads to an ictal discharge that is abolished by the gap junction blocker carbenoxolone, and that appears to arise out of a very fast network oscillation. A: In control media, tetanic stimulation (artifact not shown) leads to a $\gamma$-frequency oscillation (top trace), as shown previously 195,97/. The same stimulus in the presence of TMA (middle trace) leads to a comparable period of $y$ oscillation, followed by an ictal discharge lasting $>15 \mathrm{~s}$. Carbenoxolone prevents the ictal discharge, but not the $\gamma$ oscillation (lower trace). B: Details of the ictal discharge. The gamma oscillation is succeeded by very fast field potential oscillations that precede (1), occur during (2)), and follow (3) the ictal discharge. (Carbenoxolone also abolishes the very fast oscillations, in addition to the ictal discharge, as shown in $/ 89 /$.) From $/ 89 /$, reproduced with permission.

waves not being resolvable on this time scale) evoked by tetanic stimulation, the stimulation artefact having been removed /95/. The same stimulus, given with TMA in the bath, evokes an ictal discharge that lasts $>10 \mathrm{~s}$. (TMA alkalinizes the medium, and presumably opens gap junctions). The gap junction blocking compound, carbenoxolone, suppresses the ictal discharge evoked by tetanic stimulation with TMA present (bottom trace of Fig. 15A).

The events before and during an ictal discharge are shown in detail in Figure 15B. The tetanically evoked gamma oscillation is immediately followed by VFO of about $110 \mathrm{~Hz}$ (1). This VFO persists during the ictal discharge ((2)), and even continues after the discharge (3) ). Carbenoxolone suppresses not only the ictal discharge (Fig. 15A), but the VFO as well (see /89/). The frequency of the very fast oscillation, and its carbenoxolone sensitivity, suggest that the VFO is mediated by axonal gap junctions. Furthermore, the appearance of the VFO field potentials is more suggestive of an i-ripple than a p-ripple, i.e. the VFO may consist of very fast runs of population IPSPs. (Recall that in the experimental protocol used here, $\mathrm{GABA}_{\mathrm{A}}$ receptors have not been blocked.) Finally, the fact that the VFO occurs before the ictal discharge at least suggests the possibility that the VFO actually initiates the ictal discharge. Why or how the $\mathrm{VFO} \rightarrow$ ictal transition occurs is, however, not known. We would guess that the transition is not occurring because of a progressive failure of 
$\mathrm{GABA}_{\mathrm{A}}$ receptor-mediated inhibition, as one would then expect the i-ripple to decrease in amplitude prior to the ictal discharge, and one would not expect the rippling to continue during the ictal discharge. Perhaps the rapidly repeating EPSPs, generated by the VFO, become facilitated, eventually allowing recurrent excitation between pyramids to overcome recurrent inhibition. Recurrent EPSPs, at synapses between CAl pyramidal cells, are known to facilitate during the course of gamma oscillations evoked by strong tetanic stimuli $/ 96 /$, and might continue to facilitate even more during the faster oscillations of VFO. $15 /$.

Clinical EEG data (but not, so far, with pharmacology) also suggest that VFO - and hence, presumably, axonal gap junctions - could play a role in the initiation of focal seizures in patients. VFO are, of course, difficult or impossible to discern in scalp EEG, but have been recognized in depth and subdural recordings, sometimes just prior to seizure onset $/ 1,2,6,7,25 /$. Figure 16 illustrates subdural EEG data - capturing the onset of an ictal discharge - from a child with focal seizures of right frontal lobe onset, apparently secondary to a focal subcortical dysplasia. This child's seizures almost always began with a very high frequency discharge (e.g. in electrode G21) that was more localized, and of much lower amplitude, than the ictal discharge proper (the latter is also true for the in vitro ictal discharges shown in Fig. 15). Figure 17 shows a high-resolution recording of the initial very fast oscillation. The similarity with the in vitro seizure-

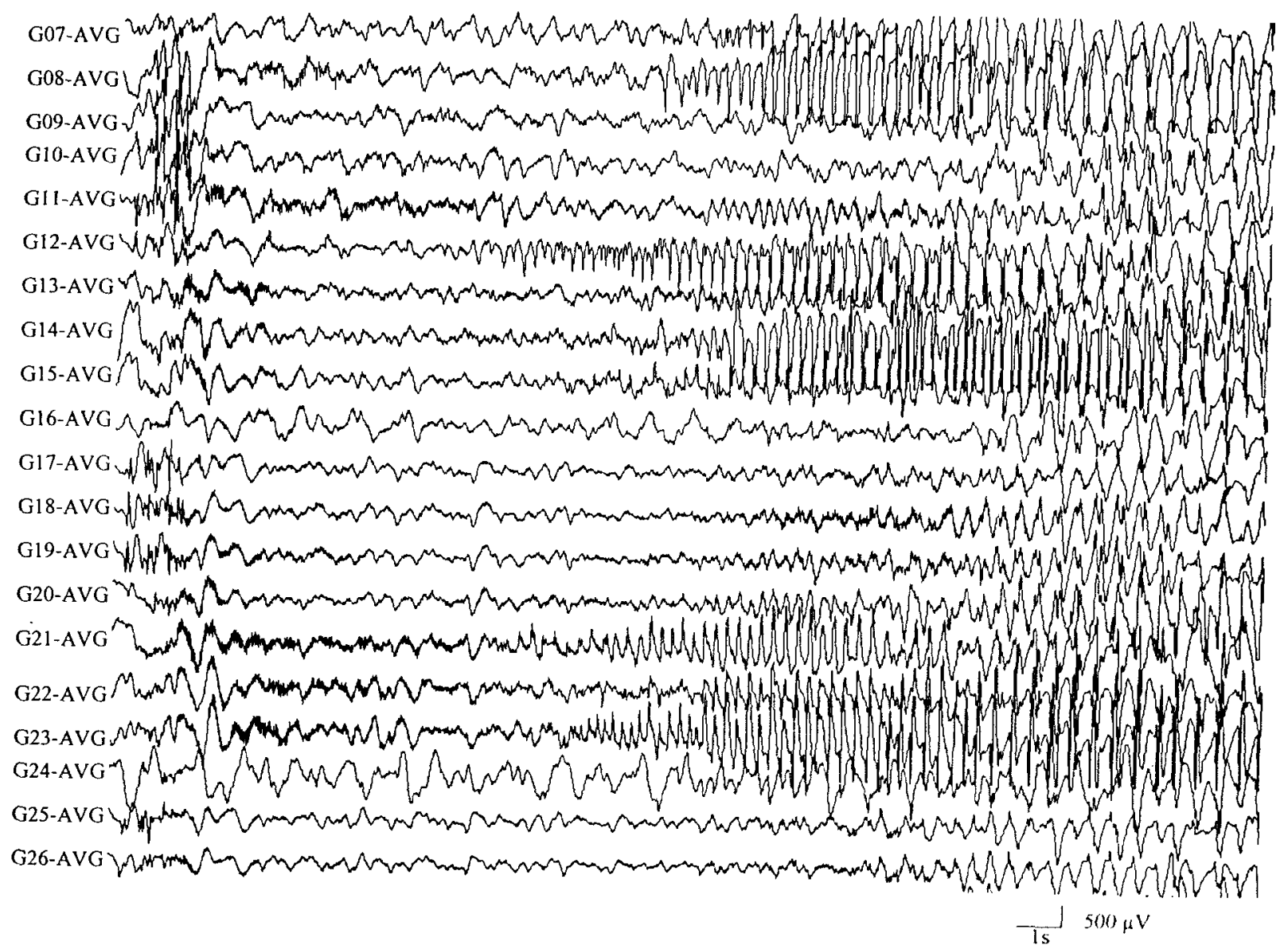

Fig. 16: Subdural EEG recording from an electrode grid showing the initial stages of a seizure discharge, beginning with a very fast oscillation in the nearby electrodes $13,14,21$ and 22 . The recording is from a 13 month-old child with a focal cortical dysplasia, deep in the right posterior frontal lobe. From $/ 89 /$, reproduced with permission. 


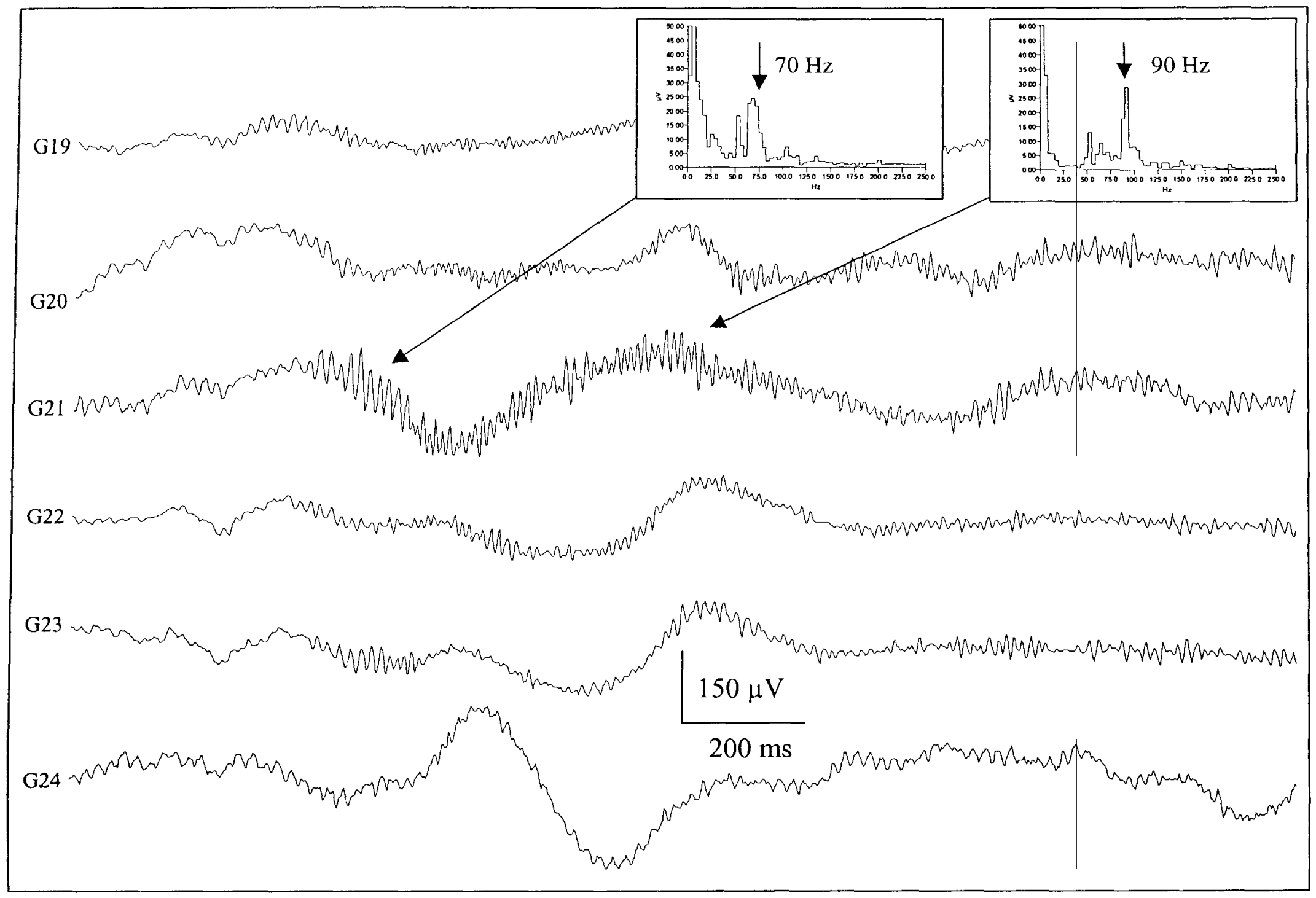


like events is striking. As in the in vitro case, this child's seizures were characterized by VFO both between, and superimposed upon, individual ictal bursts $/ 89 /$. It is not known, however, whether in humans carbenoxolone suppresses VFO.

One can speculate that neurons in the dysplastic region exhibit abnormally extensive axonal branching, as the cells "try" to make synaptic connections with appropriate targets. Such branching might provide easy opportunities to form gap junctions. There are innumerably many other possibilities, however. It is interesting, though, that focal lesions, such as induced by kainate acid injections, lead to abnormal proliferation of axonal branches $/ 8,51$, $72 /$; this is an experimental model in which a high density of axonal gap junctions might be sought.

\section{POSSIBLE FUNCTIONS OF AXONAL GAP JUNCTIONS}

We have presented data suggesting that axonal gap junctions, between principal neurons, are essential for generating very fast oscillations in an axonal plexus; and further suggesting that VFO, in turn, can produce p-ripples, i-ripples, and "pharmacological" gamma - a type of gamma oscillation produced by bath application of substances such as carbachol or kainate. p-ripples, i-ripples, and pharmacological gamma have no known functional significance in vivo, however. Not only that, we have suggested that axonal gap junctions play a role in the initiation of at least some focal seizures. Is the role of axonal gap junctions merely epiphenomenal, or pathological? Could axonal gap junctions simply reflect an injury response to axotomy, and/or dendrotomy, particularly likely during slice preparation $/ 11 /$ ? The fact that i-ripples occur in vivo in awake behaving rats $/ 102 /$ makes it unlikely, we believe, that all axonal gap junctions are an experimental artefact. Nevertheless, their functional significance, if any, is certainly unclear.

Figure 18 provides one of many possible hypotheses as to the presumed function of axonal gap junctions. This hypothesis begins with the

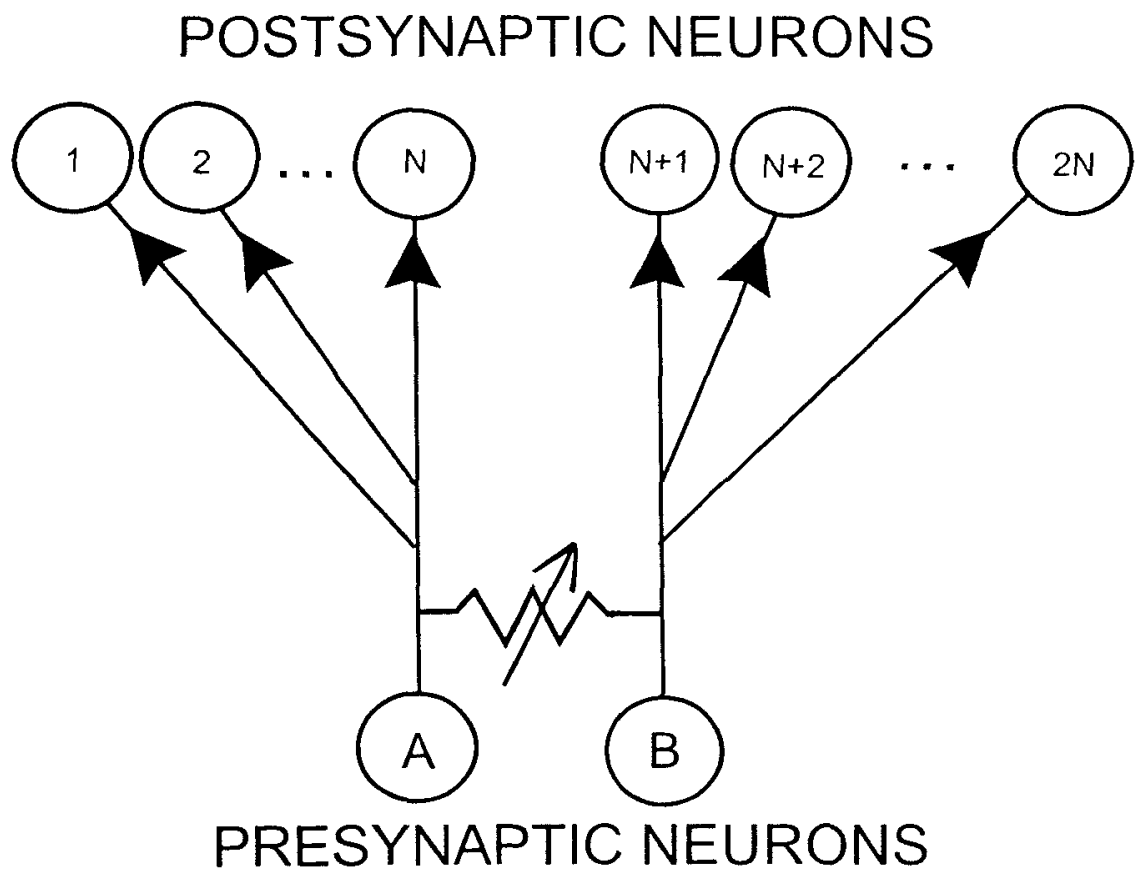

Fig. 18: A possible function for gap junctions between the axons of principal neurons. In this diagram, $A$ and $B$ represent the somata of two principal neurons, whose axons are connected by a variable resistor, i.e. a gap junction whose conductance can be regulated by neuromodulators. When the gap junction is closed. neuron $\mathrm{A}$ connects to postsynaptic neurons $1.2, \ldots$. $\mathrm{N}$; while neuron $\mathrm{B}$ connects to neurons $\mathrm{N}+1, \mathrm{~N}+2, \ldots, 2 \mathrm{~N}$. On the other hand, with the gap junction open (sufficiently for action potentials to cross), then both $\mathrm{A}$ and $\mathrm{B}$ connect to neurons $1,2 \ldots, 2 \mathrm{~N}$, that is each presynaptic cell now connects to twice as many postsynaptic cells. 
reasonable premise, supported by experimental data, that gap junction conductances can be modulated by neuromodulators $/ 32,47,53,54,56,58$, $100 \%$ When axonal gap junctions have a low conductance (that is, too low to allow spikes to cross from axon to axon), then the "wiring" of the brain assumes its usually understood form: each neuron has a particular set of postsynaptic targets. For example, in Figure 18, neuron $A$ contacts postsynaptic neurons $1,2, \ldots, \mathrm{N}$; and neuron $\mathrm{B}$ contacts postsynaptic neurons $\mathrm{N}+1, \mathrm{~N}+2, \ldots, 2 \mathrm{~N}$. On the other hand, when axonal gap junctions have a high conductance (large enough to allow spikes to cross from axon to axon), then functional postsynaptic connectivity is enhanced: both neurons $A$ and $B$ would each now contact all of the postsynaptic neurons, 1, 2, .., 2N. Selective regulation of axonal gap junctions would allow for vast possibilities to configure dynamically the synaptic wiring of the brain.

\section{THERAPEUTIC CONSIDERATIONS AND CONCLUSIONS}

As of this writing, the major possible practical significance of axonal gap junctions appears to be in focal epileptogenesis; one imagines that reduction of the axonal junctional conductance could be of therapeutic value. Certainly, the gap junction conductance-reducing compound, carbenoxolone, suppresses ictal discharges in at least one in vitro model (Fig. 15) (see also /39,59/). Carbenoxolone is a natural constituent of the root product licorice /16/. This drug is used in the UK, in patients more than 12 years old, in the treatment of ulcer disease 152/; the compound is relatively safe, having side effects related to its aldosterone-like actions. At least in rats, the compound crosses the blood-brain barrier $134 /$. It is possible, however, that CNS toxicity can occur, given that a few patients who have ingested large quantities of licorice have developed transient blindness $/ 19 /$ - recall that the retina contains many gap junctions. Quinine is another clinically used drug that blocks at least one gap junction subtype, those containing connexin-36 $168 /$ - although, as noted above, it appears that the major part of axonal gap junctions do not consist of connexin-36. In addition, quinine may not cross the blood-brain barrier effectively $/ 65 /$.

In order to make progress in the area of possible therapeutic implications, further technical and scientific advances are required in at least four problem areas:

Problem 1: Obtaining ultrastructural images of axonal gap junctions. Do axonal gap junctions have special morphological features that are different from dendritic or glial gap junctions?

Problem 2: Identification of the structural protein or proteins which mediate axonal coupling. Are these proteins known mammalian connexins? Or could the proteins be related to other sorts of molecules (e.g. innexins) used in certain invertebrate gap junctions (H. Monyer, personal communication; /26/).

Problem 3: Developing means for identifying axonal gap junctions in human brain tissue, removed during biopsies or post mortem. Are there differences in the number or properties of axonal gap junctions in epileptogenic tissue compared with non-epileptogenic tissue? If the relevant structural proteins become known, perhaps in situ hybridization or antibody studies could prove useful.

Problem 4: In experimental epilepsy models, why do very fast oscillations evolve into seizure discharges? If it is impractical to suppress VFO in humans, might it be possible to prevent this evolution?

\section{ACKNOWLEDGEMENTS}

Supported by the Wellcome Trust, DFG (Emmy-Noether-Programm, D. Schmitz), and the Medical Research Council (UK). We thank $\mathrm{H}$. Monyer, N. Kopell, and F.E.N. LeBeau for helpful discussion.

\section{REFERENCES}

1. Alarcon G, Binnie CD, Elwes RDC, Polkey CE. Power spectrum and intracranial EEG patterns at seizure onset in partial epilepsy. Electroencephalogr Clin Neurophysiol 1995; 94: 326-337.

2. Allen PJ, Fish DR, Smith SJM. Very high-frequency rhythmic activity during SEEG suppression in frontal 
lobe epilepsy. Electroencephalogr Clin Neurophysiol 1992; 82: 155-159.

3. Avoli M, Methot M, Kawasaki H. GABA-dependent generation of ectopic action potentials in the rat hippocampus. Eur J Neurosci 1998; 10: 2714-2722.

4. Bennett MVL. Physiology of electrotonic junctions. Ann NY Acad Sci 1966; 137: 509-539.

5. Bibbig A, Faulkner HJ, Whittington MA, Traub RD. Self-organized synaptic plasticity contributes to the shaping of $\gamma$ and $\beta$ oscillations in vitro. J Neurosci 2001; 21: 9053-9067.

6. Bragin A, Engel $\mathbf{J} \mathrm{Jr}$, Wilson CL, Fried I, Buzsáki G. High-frequency oscillations in the human brain. Hippocampus 1999; 9: 137-142.

7. Bragin A, Engel J Jr, Wilson CL, Fried I, Mathern GW. Hippocampal and entorhinal cortex high-frequency oscillations $(100-500 \mathrm{~Hz})$ in human epileptic brain and in kainic acid-treated rats with chronic seizures. Epilepsia 1999; 40: 127-137.

8. Buckmaster PS, Dudek FE. In vivo intracellular analysis of granule cell axon reorganization in epileptic rats. J Neurophysiol 1999; 81: 712-721.

9. Buhl EH, Tamás G, Fisahn A. Cholinergic activation and tonic excitation induce persistent gamma oscillations in mouse somatosensory cortex in vitro. J Physiol 1998; 513: 117-126.

10. Buzsáki $G$, Horváth $Z$, Urioste R, Hetke J, Wise K. High-frequency network oscillation in the hippocampus. Science 1992; 256: 1025-1027.

11. Chang Q, Pereda A, Pinter MJ, Balice-Gordon RJ. Nerve injury induces gap junctional coupling among axotomized adult motor neurons. J Neurosci 2000; 20: 674-684.

12. Chrobak JJ, Buzsáki G. High-frequency oscillations in the output networks of the hippocampal-entorhinal axis of the freely behaving rat. J Neurosci 1996; 16: 30563066 .

13. Church J, Baimbridge KG. Exposure to high-pH medium increases the incidence and extent of dye coupling between rat hippocampal CAl pyramidal neurons in vitro. J Neurosci 1991; 11: 3289-3295.

14. Cochill AJ, Alford S. Glutamate receptor-mediated synaptic excitation in axons of the lamprey. J Physiol 1997; 499: 443-457.

15. Coombs JS, Curtis DR, Eccles JC. The generation of impulses in motoneurones. J Physiol 1957; 139: 232249.

16. Davidson JS, Baumgarten IM. Glycyrrhetinic acid derivatives: a novel class of inhibitors of gap-junctional intercellular communication. Structure-activity relationships. J Pharamacol Exp Ther 1988; 246: 1104-1107.

17 Debanne D, Guérineau NC, Gähwiler BH, Thompson SM. Action-potential propagation gated by an axonal $\mathrm{I}_{\mathrm{A}}$-like $\mathrm{K}^{+}$conductance in hippocampus. Nature 1997 ; 389: 286-289.

18. Deuchars J, Thomson AM. CAl pyramid-pyramid connections in rat hippocampus in vitro: dual intracellular recordings with biocytin filling. Neuroscience 1996; 74 : 1009-1018.

19. Dobbins KR, Saul RF. Transient visual loss after licorice ingestion. J Neuroophthalmol 2000; 20:38-41.

20. Draguhn A, Traub RD, Schmitz D, Jefferys JGR. Electrical coupling underlies high-frequency oscillations in the hippocampus in vitro. Nature 1998; 394: 189-192.

21. Draguhn A, Traub RD, Bibbig A, Schmitz D. Ripple (approximately $200-\mathrm{Hz}$ ) oscillations in temporal structures. J Clin Neurophysiol 2000; 17: 361-376.

22. Elekes K, Szabo T. Synaptology of the medullary command (pacemaker) nucleus of the weakly electric fish (Apteronotus leptorhynchus) with particular reference to comparative aspects. Exp Brain Res 1985; 60: 509-520.

23. Erdös $P$, Rényi $A$. On the evolution of random graphs. Publ Math Inst Hung Acad Sci 1960; 5: 17-61.

24. Fisahn A, Pike FG, Buhl EH, Paulsen O. Cholinergic induction of network oscillations at $40 \mathrm{~Hz}$ in the hippocampus in vitro. Nature 1998; 394: 186-189.

25. Fisher RS, Webber WRS, Lesser RP, Arroyo S, Uematsu S. High-frequency EEG activity at the start of seizures. J Clin Neurophysiol 1992; 9: 441-448.

26. Ganfornina MD, Sanchez D, Herrera M, Bastiani MJ. Developmental expression and molecular characterization of two gap junction channel proteins expressed during embryogenesis in the grasshopper Schistocerca americana. Dev Genet 1999; 24: 137-150.

27. Geiger JRP, Lübke J, Roth A, Frotscher M, Jonas P. Submillisecond AMPA receptor-mediated signaling at a principal neuron-interneuron synapse. Neuron 1997; 18: 1009-1023.

28. Golding NL, Spruston N. Dendritic sodium spikes are variable triggers of axonal action potentials in hippocampal CA1 pyramidal neurons. Neuron 1998; 21: 1189-1200.

29. Grenier F, Timofeev I, Steriade M. Focal synchronization of ripples $(80-200 \mathrm{~Hz})$ in neocortex and their neuronal correlates. J Neurophysiol 2001; 86: 18841898.

30. Gulyás AI, Miles R, Sik A, Tóth K, Tamamaki N, Freund TF. Hippocampal pyramidal cells excite inhibitory neurons through a single release site. Nature 1993; 366: 683-687.

31. Haas HL, Jefferys JGR. Low-calcium field burst discharges of CAl pyramidal neurones in rat hippocampal slices. J Physiol 1984; 354: 185-201.

32. He S, Weiler R, Vaney DI. Endogneous dopaminergic regulation of horizontal cell coupling in the mammalian retina. J Comp Neurol 2000; 418: 33-40.

33. Hormuzdi SG, Pais I, LeBeau FEN, Towers SK, Rozov A, Buhl EH, Whittington MA, Monyer H. Impaired electrical signaling disrupts gamma frequency oscillations in connexin 36-deficient mice. Neuron 2001; 31: 487-495. 
34. Jellinck PH, Monder C, McEwen BS, Sakai RR. Differential inhibition of 11 beta-hydroxysteroid dehydrogenase by carbenoxolone in rat brain regions and peripheral tissues. J Steroid Biochem Mol Biol 1993; 46: 209-213.

35. Jones MS, Barth DS. Spatiotemporal organization of fast $(>200 \mathrm{~Hz})$ electrical oscillations in rat vibrissa/ barrel cortex. J Neurophysiol 1999; 82: 1599-1609.

36. Jones MS, MacDonald KD, Choi B, Dudek FE, Barth DS. Intracellular correlates of fast $(>200 \mathrm{~Hz})$ electrical oscillations in rat somatosensory cortex. J Neurophysiol 2000; 84: 1505-1518.

37. Kamiya H, Ozawa S. Kainate receptor-mediated presynaptic inhibition at the mouse hippocampal mossy fibre synapse. J Physiol 2000; 523: 653-665.

38. Knowles WD, Schwartzkroin PA. Axonal ramifications of hippocampal CA1 pyramidal cells. J Neurosci 1981; 1: $1236-1241$.

39. Köhling R, Gladwell SJ, Bracci E, Vreugdenhil M, Jefferys JGR. Prolonged epileptiform bursting induced by $0-\mathrm{Mg}^{2+}$ in rat hippocampal slices depends on gap junctional coupling. Neuroscience 2001; 105: 579-587.

40. Kosaka $T$. The axon initial segment as a synaptic site: ultrastructure and synaptology of the initial segment of the pyramidal cell in the rat hippocampus (CA3 region). J Neurocytol 1980; 9: 861-882.

41. LeBeau FEN, Towers SK, Traub RD, Whittington MA, Buhl EH. Fast and ultrafast oscillations in the hippocampus in vitro. Abstr Soc Neurosci 2000.

42. Lewis TJ, Rinzel J. Self-organized synchronous oscillations in a network of excitable cells coupled by gap junctions. Network-Comput Neural Syst 2000; 11: 299-320.

43. Llinás R, Nicholson C. Electrophysiological properties of dendrites and somata in alligator Purkinje cells. J Neurophysiol 1971; 34: 532-551.

44. MacVicar BA, Dudek FE. Dye-coupling between CA3 pyramidal cells in slices of rat hippocampus. Brain Res 1980; 196: 494-497.

45. MacVicar BA, Dudek FE. Electrotonic coupling between pyramidal cells: a direct demonstration in rat hippocampal slices. Science 1981; 213: 782-785.

46. MacVicar BA, Dudek FE. Electrotonic coupling between granule cells of the rat dentate gyrus: physiological and anatomical evidence. J Neurophysiol 1982; 47: 579-592.

47. Matesic DF, Hayashi T, Trosko JE, Germak JA. Upregulation of gap junctional intercellular communication in immortalized gonadotropin-releasing hormone neurons by stimulation of the cyclic AMP pathway. Neuroendocrinology 1996; 64: 286-297.

48. Mickus T, Jung H-Y, Spruston N. Properties of slow, cumulative sodium channel inactivation in rat hippocampal CAI pyramidal neurons. Biophys J 1999; 76 : 846-860.

49. Moortgat KT, Bullock TH, Sejnowski TJ. Gap junction effects on precision and frequency of a model pacemaker network. J Neurophysiol 2000; 83: 984-997.
50. Moortgat KT, Bullock TH, Sejnowski TJ. Precision of the pacemaker nucleus in a weakly electric fish: network versus cellular influences. J Neurophysiol 2000; 83: 971-983.

51. Nadler JV, Perry BW, Cotman CW. Selective reinnervation of hippocampal area $\mathrm{CA} 1$ and the fascia dentata after destruction of CA3-CA4 afferents with kainic acid. Brain Res 1980; 182: 1-9.

52. Nagy GS. Evaluation of carbenoxolone sodium in the treatment of duodenal ulcer. Gastroenterology 1978; 74: 7-10.

53. O'Donnell P, Grace AA. Cortical afferents modulate striatal gap junction permeability via nitric oxide. Neuroscience 1997; 76: 1-5.

54. Pereda AE, Bell TD, Chang BH, Czernik AJ, Nairn $\mathrm{AC}$, Soderling TR, Faber DS. $\mathrm{Ca}^{2+} /$ calmodulin-dependent kinase II mediates simultaneous enhancement of gap-junctional conductance and glutamatergic transmission. Proc Natl Acad Sci USA 1998; 95: 1327213277.

55. Perez Velazquez JL, Carlen PL. Gap junctions, synchrony and seizures. Trends Neurosci 2000; 23: 68-74.

56. Perez Velazquez JL, Han D, Carlen PL. Neurotransmitter modulation of gap junctional communication in the rat hippocampus. Eur J Neurosci 1997; 9: 25222531.

57. Perez-Velazquez JL, Valiante TA, Carlen PL. Modulation of gap junctional mechanisms during calcium-free induced field burst activity: a possible role for electrotonic coupling in epileptogenesis. J Neurosci 1994; 14: 4308-4317.

58. Rorig B, Sutor B. Serotonin regulates gap junction coupling in the developing rat somatosensory cortex. Eur J Neurosci 1996; 8: 1685-1695.

59. Ross FM, Gwyn P, Spanswick D, Davies SN. Carbenoxolone depresses spontaneous epileptiform activity in the CA 1 region of rat hippocampal slices. Neuroscience 2000; 100: 789-796.

60. Schmitz D, Frerking M, Nicoll RA. Synaptic activation of presynaptic kainate receptors on hippocampal mossy fiber synapses. Neuron 2000; 27: 327-338.

61. Schmitz D, Mellor J, Frerking M, Nicoll RA. Presynaptic kainate receptors at hippocampal mossy fiber synapses. Proc Natl Acad Sci USA 2001; 98: 1100311008.

62. Schmitz D, Schuchmann S, Fisahn A, Draguhn A, Buhl EH, Petrasch-Parwez RE, Dermietzel R, Heinemann U, Traub RD. Axo-axonal coupling: a novel mechanism for ultrafast neuronal communication. Neuron 2001; 31 : 831-840.

63. Schwartzkroin PA, Prince DA. Penicillin-induced epileptiform activity in the hippocampal in vitro preparation. Ann Neurol 1977; 1: 463-469.

64. Semyanov A, Kullmann DM. Kainate receptordependent axonal depolarization and action potential initiation in interneurons. Nat Neurosci 2001; 4: 718723. 
65. Silamut K, White NJ, Looareesuwan S, Warrell DA. Binding of quinine to plasma proteins in Falciparum malaria. Am J Trop Med Hyg 1985; 34: 681-686.

66. Spencer WA, Kandel ER. Electophysiology of hippocampal neurons. IV. Fast prepotentials. J Neurophysiol 1961; 24: 272-285.

67. Spray DC, Harris AL, Bennett MVL. Gap junctional conductance is a simple and sensitive function of intracellular $\mathrm{pH}$. Science 1981;211: 712-715

68. Srinivas M, Hopperstad MG, Spray DG. Quinine blocks specific gap junction channel subtypes. Proc Natl Acad Sci USA 2001; 98: 10942-10947.

69. Stasheff SF, Hines M, Wilson WA. Axon terminal hyperexcitability associated with epileptogenesis in vitro. I. Origin of ectopic spikes. J Neurophysiol 1993; 70: 960-975.

70. Stasheff SF, Mott DD, Wilson WA. Axon terminal hyperexcitability associated with epileptogenesis in vitro. II. Pharmacological regulation by NMDA and $\mathrm{GABA}_{\mathrm{A}}$ receptors. J Neurophysiol 1993; 70: 976-984.

71. Stuart G, Spruston N, Sakmann B, Häusser M. Action potential initiation and backpropagation in neurons of the mammalian CNS. Trends Neurosci 1997; 20: 125131.

72. Tauck DL, Nadler JV. Evidence of functional mossy fiber sprouting in hippocampal formation of kainic acid-treated rats. J Neurosci 1985; 5: 1016-1022.

73. Taylor CP, Dudek FE. Synchronous neural afterdischarges in rat hippocampal slices without active chemical synapses. Science 1982; $218: 810-812$.

74. Taylor CP, Dudek FE. Excitation of hippocampal pyramidal cells by an electrical field effect. J Neurophysiol 1984 ; 52: 126-142.

75. Towers SK, LeBeau FEN, Gloveli T, Traub RD, Whittington MA, Buhl EH. Fast network oscillations in the rat dentate gyrus in vitro. $J$ Neurophysiol $2002 ; 87$ : 1165-1168.

76. Towers SK, LeBeau FEN, Traub RD, Whittington MA, Buhl EH. Fast network oscillations in the rat dentate gyrus in vitro. Abstr Soc Neurosci 2000; 26: 183.

77. Traub RD, Wong RKS. Cellular mechanism of neuronal synchronization in epilepsy. Science 1982;216: 745-747.

78. Traub RD, Dudek FE, Taylor CP, Knowles WD Simulation of hippocampal afterdischarges synchronized by electrical interactions. Neuroscience 1985; 14: 1033-1038.

79. Traub RD, Jefferys JGR, Miles R, Whittington MA, Tóth K. A branching dendritic model of a rodent CA3 pyramidal neurone. J Physiol 1994; 481: 79-95.

80. Traub RD, Colling SB, Jefferys JGRJ. Cellular mechanisms of 4-aminopyridine-induced synchronized afterdischarges in the rat hippocampal slice. J Physiol 1995; 489: 127-140.

81. Traub RD, Whittington MA, Colling SB, Buzsáki G, Jefferys JGR. Analysis of gamma rhythms in the rat hippocampus in vitro and in vivo. J Physiol 1996; 493: $471-484$
82. Traub RD, Whittington MA, Stanford M, Jefferys JGR. A mechanism for generation of long-range synchronous fast oscillations in the cortex. Nature 1996; 383: 621624.

83. Traub RD, Jefferys JGR, Whittington MA. Simulation of gamma rhythms in networks of interneurons and pyramidal cells. J Comput Neurosci 1997; 4: 141-150.

84. Traub RD, Jefferys JGR, Whittington MA. Fast Oscillations in Cortical Circuits. Cambridge, MA: MIT Press, 1999.

85. Traub RD, Schmitz D, Jefferys JGR, Draguhn A. Highfrequency population oscillations are predicted to occur in hippocampal pyramidal neuronal networks interconnected by axoaxonal gap junctions. Neuroscience 1999; 92: 407-426.

86. Traub RD, Bibbig A, Fisahn A, LeBeau FEN, Whittington MA, Buhl EH. A model of gammafrequency network oscillations induced in the rat $\mathrm{CA} 3$ region by carbachol in vitro. Eur J Neurosci $2000 ; 12$. 4093-4106.

87. Traub RD, Bibbig A. A model of high-frequency ripples in the hippocampus, based on synaptic coupling plus axon-axon gap junctions between pyramidal neurons. J Neurosci 2000; 20: 2086-2093.

88. Traub RD, Bibbig A, Piechotta A, Draguhn A, Schmitz D. Synaptic and nonsynaptic contributions to giant IPSPs and ectopic spikes induced by 4-aminopyridine in the hippocampus in vitro. J Neurophysiol 2001; 85: 1246-1256.

89. Traub RD, Whittington MA, Buhl EH, LeBeau FEN, Bibbig A, Boyd S, Cross H, Baldeweg T. A possible role for gap junctions in generation of very fast EEG oscillations preceding the onset of, and perhaps initiating, seizures. Epilepsia 2001; 42: 153-170.

90. Traub RD Kopell N, Bibbig A, Buhl EH, LeBeau FEN, Whittington MA. Gap junctions between interneuron dendrites can enhance long-range synchrony of gamma oscillations. J Neurosci 2001; 21: 9478-9486.

91. Turpie AG, Thomson TJ. Carbenoxolone sodium in the treatment of gastric ulcer with special reference to sideeffects. Gut 1965; 6: 591-594.

92. Valiante TA, Perez Velazquez JL, Jahromi SS, Carlen $\mathrm{PL}$. Coupling potentials in CA1 neurons during calciumfree-induced field burst activity. J Neurosci 1995; 15 : 6946-6956.

93. Vaney DI. The coupling pattern of axon-bearing horizontal cells in the mammalian retina. Proc Roy Soc Lond B 1993; 252: 93-101.

94. Whittington MA, Traub RD, Jefferys JGR. Synchronized oscillations in interneuron networks driven by metabotropic glutamate receptor activation. Nature $1995 ; 373: 612-615$

95. Whittington MA, Stanford IM, Colling SB, Jefferys JGR, Traub RD. Spatiotemporal patterns of $y$ frequency oscillations tetanically induced in the rat hippocampal slice. J Physiol 1997; 502: 591-607. 
96. Whittington MA, Traub RD, Faulkner HJ, Stanford IM, Jefferys JGR. Recurrent excitatory postsynaptic potentials induced by synchronized fast cortical oscillations. Proc Natl Acad Sci USA 1997; 94: 12198-12203.

97. Whittington MA, Doheny HC, Traub RD, LeBeau FEN, Buhl EH. Differential expression of synaptic and non-synaptic mechanisms during stimulus-induced gamma oscillations in vitro. J Neurosci 2001; 21: 1727-1738.

98. Wong RKS, Prince DA, Basbaum AI. Intradendritic recordings from hippocampal neurons. Proc Natl Acad Sci USA 1979; 76: 986-990.

99. Wong RKS, Traub RD. Synchronized burst discharge in disinhibited hippocampal slice. I. Initiation in CA2CA3 region. J Neurophysiol 1983; 49: 442-458.
100. Xin D, Bloomfield SA. Effects of nitric oxide on horizontal cells in the rabbit retina. Visual Neurosci 2000; 17: 799-811.

101. Yasargil GM, Sandri C. Topography and ultrastructure of commissural interneurons that may establish reciprocal inhibitory connections of the Mauthner axons in the spinal cord of the tench, Tinca tinca L. J Neurocytol 1990; 19: 111-126.

102. Ylinen A, Bragin A, Nádasdy Z, Jandó G, Szabó l, Sik $A$, Buzsáki G. Sharp wave-associated high frequency oscillation $(200 \mathrm{~Hz})$ in the intact hippocampus: network and intracellular mechanisms. J Neurosci 1995; 15: 3046. 